electrode arrays

3 Authors : H. Kiflu ${ }^{l^{*}}$, S. Kruse ${ }^{1}$, M. H. Loke ${ }^{2}$, P.B.Wilkinson ${ }^{3}$ and D. Harro ${ }^{4}$

51 School of Geoscience, University of South Florida, 4202 E. Fowler Avenue, SCA 528,

6 Tampa, FL 33620-8100, USA

72 Geotomo Software, 115 Cangkat Minden Jalan 5, Minden Heights, Gelugor 11700,

8 Penang, Malaysia

93 British Geological Survey, Environmental Science Centre, Keyworth, Nottingham,

10 NG12 5GG, United Kingdom

114 Geo3Group, 2509 Success Drive, Suite 1, Odessa, FL 33556, USA

*Corresponding author, email : hgkiflu@mail.usf.edu

\title{
Abstract
}

Electrical resistivity tomography (ERT) surveys are widely used in geological, environmental and engineering studies. However, the effectiveness of surface ERT surveys is limited by decreasing resolution with depth and near the ends of the survey line. Increasing the array length will increase depth of investigation, but may not be possible at urban sites where access is limited. One novel method of addressing these limitations while maintaining lateral coverage is to install an array of deep electrodes. Referred to here as the Multi-Electrode Resistivity Implant Technique (MERIT), self-driving pointed electrodes are implanted at depth below each surface electrode in an array, using direct-push technology. Optimal sequences of readings have been identified with the "Compare R" method of Wilkinson. Numerical, laboratory, and field case studies are applied to examine the effectiveness of the MERIT method, particularly for use in covered karst terrain. In the field case studies, resistivity images are compared against subsurface structure defined from borings, GPR surveys, and knowledge of prior land use. In karst terrain where limestone has a clay overburden, traditional surface resistivity methods suffer from lack of current penetration through the shallow clay layer. In these settings, the MERIT method is found to improve resolution of features between the surface and buried array, as well as increasing depth of penetration and enhancing imaging capabilities at the array ends. The method functions similarly to a cross-borehole array between horizontal boreholes, and suffers from limitations common to borehole arrays. Inversion artifacts are common at depths close to the buried array, and because some readings involve high geometric factors, inversions are more susceptible to noise than traditional surface arrays. Results are improved by using errors from reciprocal measurements to weight the data during the inversion.

Keywords: Resistivity Inversion, Tomography, Optimized arrays, Sinkhole karst features, MERIT 
1. Introduction

Electrical resistivity is a widely used geophysical method for investigating geological and hydrogeological (e.g. Kruse et al., 1998; Daniels et al., 2005; Nenna et al., 2011; Singha et al., 2014; Yeboah-Forson et al., 2014) engineering (Wilkinson et al,2006a ; Danielsen and Dahlin,2010 ), mining (Legault et al., 2008) and environmental problems (Slater et al, 2000; Pidlisecky et al., 2006; Meju, 2006; Chambers et al. 2010; Power et al., 2015). The method can be applied to such a wide range of problems because measurements are sensitive to lithology, degree of saturation, and pore water composition (e.g. Lesmes and Friedman, 2005). Reviews of the recent developments in electrical resistivity tomography (ERT) are given by Dahlin, (2001), Auken et al. (2006) and more recently by Loke et al. (2013).

During a resistivity survey DC current is driven through the earth between pairs of electrodes installed at the surface or buried at depth. While current flows, electric potential differences are measured between other pairs of electrodes. The measured potential differences are related to the resistivity structure of the ground through which the current flows. There is clearly infinite flexibility in how the electrodes used to drive current and those used to measure potential can be spatially configured. Use of traditional electrode arrangements with simple rules for displaying apparent resistivities as pseudosections, such as Wenner (e.g. Loke, 2010) and dipole-dipole arrays (e.g. Telford and Sheriff, 1990), persists even after the development of commercial systems that can automate acquisition of more flexible array geometries.

Current commercial resistivity systems offer automated switching capabilities for driving current and measuring potentials, so users install an array of electrodes, often $\sim 30-100$. Then a sequence of readings is taken by addressing pairs of current and potential electrodes within the array. Most surveys conducted today are two-dimensional (2D); a series of electrodes are laid out in a straight line. Typically electrodes are evenly spaced along the line. Such conventional 2D surveys are logistically efficient to deploy, but there are well-recognized limitations to conventional 2D surveys, which are discussed further below.

Other arrangements of electrodes have been tested and described, including 3D surveys in which electrodes are arranged in grids on the surface (Loke and Barker, 1996; Tsourlos and Ogilvy, 1999). More labor-intensive methods involve installing electrodes in vertical downhole arrays, for crossborehole surveys (e.g Daily \& Owen, 1991; Slater et al., 2000; Perri et al., 2012). Pidlisecky et al. (2006) used deep electrodes as current source in resistivity measurements done using a cone penetration testing (CPT) rig. Danielsen and Dahlin (2010) used horizontal boreholes drilled on the working face of a tunnel boring machine (TBM) to gain information about the rock conditions before the next heading. Power et al. (2015) demonstrated improved time-lapse monitoring of contaminant remediation using surface-to-horizontal borehole ERT relative to surface ERT. Symyrdanis et al. (2015) used surface-to-tunnel electrical resistivity tomography to study the subsurface between the ground and a tunnel. Clearly, the current state of the practice in resistivity surveys offers unprecedented flexibility in the spatial positioning of a set of electrodes. 
In this paper, we describe and test a new arrangement of electrodes in which a series of electrodes are individually vertically implanted at a uniform depth, to form a buried horizontal array. This arrangement addresses two fundamental limitations of conventional 2D arrays. The optimization of readings within the new array is the focus of a separate paper, Loke et al. (2015) which discusses the advantages of optimized MERIT arrays over manually created MERIT arrays. With 2D surveys, two significant limitations arise that are particularly acute in urban settings. First, 2D surveys resolve resistivities to depths considerably shallower than the total array length. Where practitioners are limited to access on a single plot of land, the array length, and hence the depth of resolution, is constrained by the plot boundaries. This can be a critical shortcoming if the target of interest lies below the plot-limited depth of penetration. The problem is exacerbated when shallow conductive layers further inhibit deep current flow. Second, 2D surveys lose resolution at the ends of the survey line (Loke, 2010). Cross-borehole surveys, with readings made between electrodes in paired boreholes, can overcome the sensitivity limitations at depth. But the cost of drilling boreholes is relatively high, and, because of this installation expense, the number of holes is often limited, and hence lateral coverage is also limited.

a) ப்ப்ப்ப்ப்ப்ப்ப்ப்ப்ப்ப்ப்ப்ப்ப்

b)

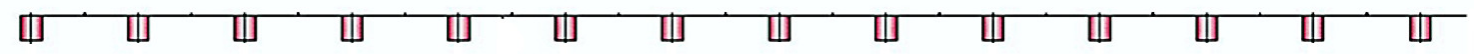

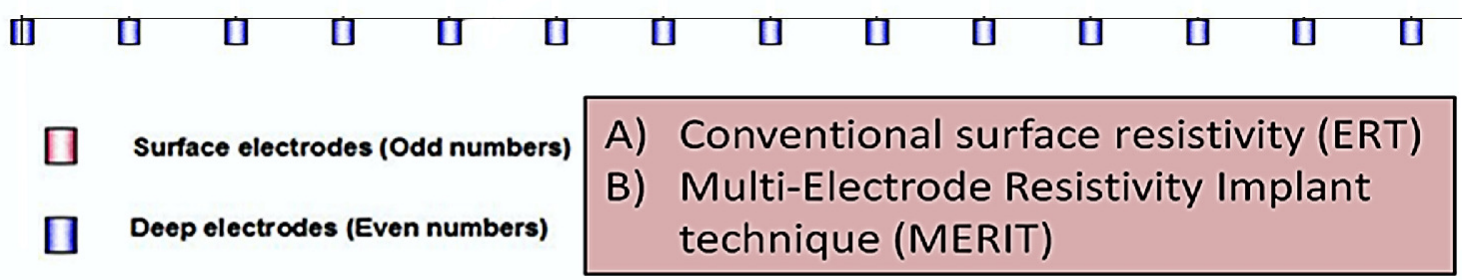




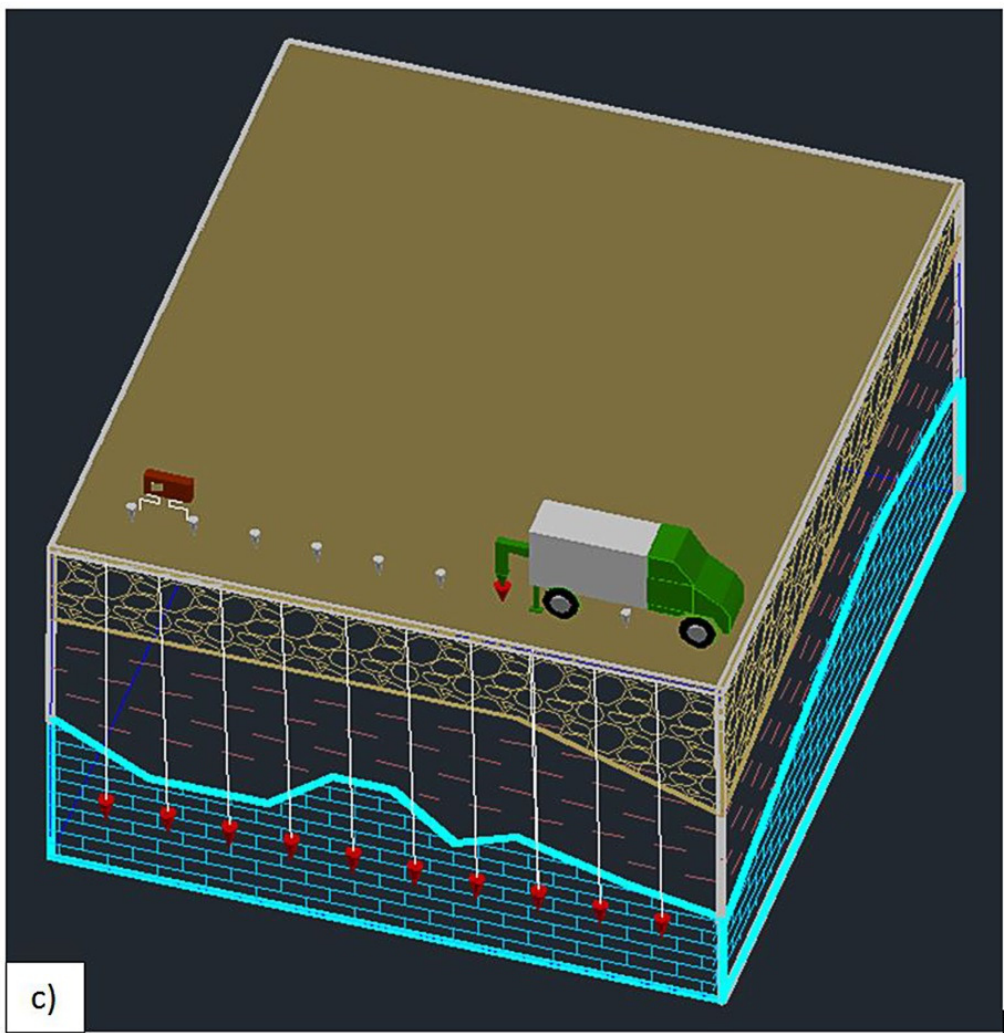

Figure 1. (a) Field arrangement of a conventional surface array. (b) Field arrangement of MERIT array. c) Schematic diagram showing the installation of MERIT arrays.

Here we use a novel technique to enhance depth of sensitivity, with increased lateral resolution along the surface array length. This is done by implanting half of the electrodes at a depth closer to the subsurface target features, using an efficient direct-push technique (Figures 1a, 1b and c). To make installation efficient and robust, deep pointed implant electrodes were designed to facilitate vibration resistance while being driven into the ground with minimal impact (Harro and Kruse, 2013). This array geometry is referred to as the multi - electrode resistivity implant technique, or MERIT. The presence of deep electrodes allows higher signal strength and sensitivity at depth even when the survey length is small. Even in areas where a longer survey would be feasible, a shorter MERIT array can avoid unwanted sensitivities to features off the survey line (e.g. Dahlin, 2001). The installation method is further discussed down below.

MERIT arrays require more time and cost compared to conventional surface resistivity surveys. Hence, it is essential to use optimized arrays that will maximize the information gained from measurements taken using these surface and deep arrays. Although many practitioners use readings based on combinations of traditional arrays such as the dipole-dipole and Wenner arrays, a growing body of literature describes methods to find more efficient combinations of electrode selections. These 'optimized' arrays are mostly designed to maximize resolution of resistivity heterogeneities throughout the target volume (e.g. Cherkaeva, E. \& Tripp, A.C., 1996; Furman et al, 2004; Stummer et 
al, 2004; Hennig, T. \& Weller, A., 2005; Wilkinson et al, 2006b; Hagrey, S. A. al and Petersen, T., 2011). In this paper, optimal sequences of readings have been identified with the "Compare R" automatic array optimization techniques (Wilkinson et al., 2006b; 2012; Loke et al., 2015) to find optimal sets of readings that will capture the sub-surface geological heterogeneities between the surface and deep arrays and below the deep arrays. This improved approach is a novel application of the resistivity method to study complex subsurface geological features such as active sinkhole features in covered karst terrain.

\section{Sinkhole structure}

The efficacy of MERIT surveys is examined in this paper in particular for covered karst terrain. Karst processes commonly result in complex subsurface geologic features, including sinkholes, irregular dissolution cavities, randomly spaced fractures and complex interfaces between units. Imaging karst features can be critical to avoiding infrastructure damage. Sinkholes are extremely common, with nearly 6,694 reported sinkholes in 2010 in Florida, USA (Figure 2a), and subsidence associated with these sinkholes costs \$200 million/year in infrastructure damage (Florida Senate Interim report, 2010). Tihansky, (1999) gives a detailed description of the distribution and characteristics of sinkholes in West-Central Florida. Furthermore, sinkholes serve as a critical hydrological connection between the surface and underlying aquifers, functioning as zones of concentrated recharge (e.g. Stewart, 1998). Resistivity surveys are used globally to image geologic features associated with sinkhole formation and karst evolution (Gibson et al, 2004; El-Qady et al, 2005; Ahmed et al, 2012). Nevertheless in many settings these features remain challenging targets for traditional resistivity arrays, and we focus our assessment of the MERIT method on these societally important structures. The fundamental results, however, are applicable to any geologic setting.

In west-central Florida, sinkhole structures typically involve, from the bottom upwards, dissolution cavitieslconduitslfractures in the limestone; undulations of bedrock contact; weathered limestone; sediment raveling zones connecting surface features with deeper voids in the bedrock; localized dissolution cavities or voids in the overburden sands and clays; and surface and subsurface depressions (Figure 2b).

Ground penetrating radar (GPR) is the most commonly used geophysical method in sinkhole investigations due to its capability to detect shallow soil and stratigraphic anomalies (e.g. sub-surface depressions) related to sinkhole processes (Benson and La Fountain, 1984; Beck and Sayed, 1991; Stewart and Parker, 1992; Carpenter et al., 1998; Batayneh et al., 2002; Dobecki and Upchurch, 2006; Kruse et al, 2006). However, GPR depth of investigation is typically limited to the uppermost few meters. These shallowest features are commonly only indirectly related to the actual deep dissolution cavities in the bedrock, which are the primal causes of the sinkhole hazards. Further complicating the picture, the surface features are frequently laterally offset from the deep cavities, as illustrated in Figure 2b (Kiflu et al., 2013). There is clearly a need for methods, such as resistivity, that could image both within and below the sediment cover. Here we examine the resolution of this range of targets expected from sinkhole activity using numerical, laboratory and field studies. 


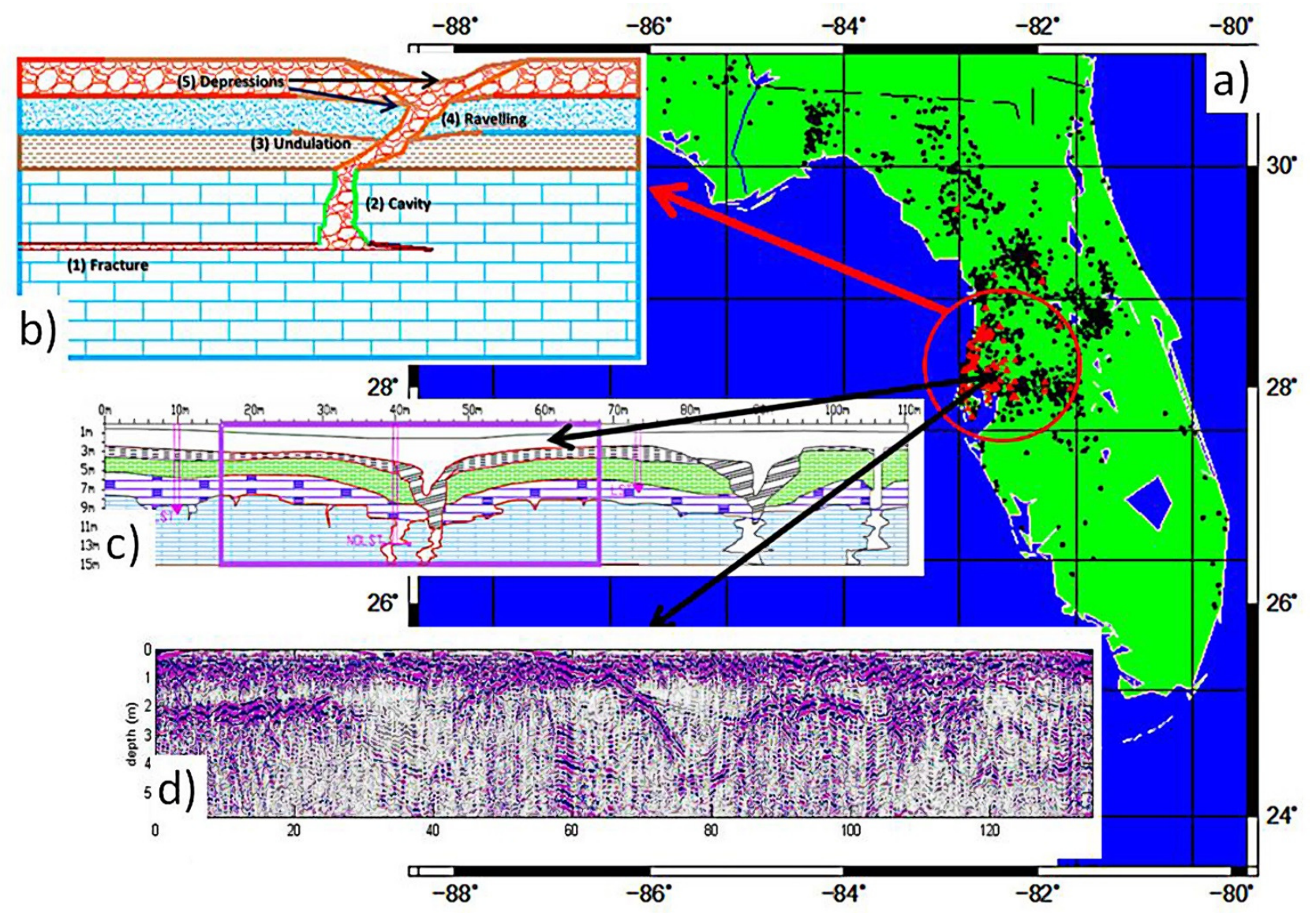

Figure 2. Sinkhole structure in Florida. (A) Distribution of reported sinkholes in Florida. Black dots represent sinkhole database from Florida geological survey website. Red dots indicate reported sinkholes studied by Kiflu et al.( 2013). (B) Schematic representation of sinkhole structure in areas with narrow dissolution cavities. The inclined raveling zone (4) is based on the results of Kiflu et al. (2013). Studies on the sinkholes represented by the red dots showed the common occurrence of lateral offset between deep and shallow sinkhole features . (C) Geologic profile showing sinkhole structure in Geopark research site, Tampa, Florida, USA. Modified from Stewart and Parker (1992). (D) GPR image showing shallow sinkhole features represented by the subsurface depression of bright reflector layers.

2. Method

2.1 MERIT array Installation In the MERIT approach, the subsurface electrodes are implanted using a Geoprobe ${ }^{\circledR}$ (Direct-Push) system (e.g. United States Environmental Protection Agency, 2005). The implanted electrode is an expendable drive point with an attached wire (Harro and Kruse, 2013). The drive point is placed in the lower end of a groundwater sampling sheath that is pushed downwards by percussion (Fig 1c). When it reaches the desired depth, the sheath is withdrawn leaving the implanted electrode joined to the surface by the attached wire. This installation is more rapid and less costly compared to vertical 
boreholes with an average rate of installation of $20 \mathrm{~m} / \mathrm{hr}$. Installation is less expensive and more rapid than conventional vertical boreholes. Cost wise, a MERIT array with 14 buried electrodes at $7.6 \mathrm{~m}$ depth is typically less costly than two cross-boreholes with 15-electrode string (United States Environmental Protection Agency, 1998) making it an attractive choice for deeper targets with large horizontal extent. In addition, compared to most drilling techniques, the MERIT approach minimizes the disturbance to the target itself by avoiding the use of circulation fluid and by utilizing a small borehole radius $(\sim 2.5 \mathrm{~cm})$. The borehole radius is much smaller than the targets of the studies described here.

The direct push rig has a controlled hydraulic system that permits vertical advancements in increments as small as $0.125 \mathrm{~cm}$. When the lengths of the push rods for installation are accurately measured, the vertical accuracy of the implanted electrodes is expected to be similar to that of an electrode mounted on a rigid support in vertical boreholes (e.g. Wilkinson et al., 2008). Following Paasche et al. (2009), the maximum horizontal deviation of the direct push rod from vertical is expected to be less than 5 degrees.

Because MERIT is similar to a cross-borehole array rotated to horizontal, we can take advantage of lessons learned from cross-borehole surveys. For example, a large separation between the deep and the surface electrodes can result in decreased sensitivities at the center and problems of nonuniqueness and spurious inversion results around the lower array. For cross-boreholes, LaBrecque et al (1996) suggest a maximum borehole separation of 0.75 of the borehole array length. In this paper, we derive analogous guidelines for MERIT arrays. The optimal depth of implants balances tradeoffs between data quality, cost, effective depth of investigation and target depth. Choice of implant depth can further be improved by carrying out pre-survey forward modelling. After deployment of the array, the user must select the optimal combinations of electrodes as current and potential pairs to maximize information extracted per reading.

\subsection{Array optimization}

Deployment of MERIT arrays offers complex spatial geometries with opportunities to select optimal combinations of electrodes as current and potential pairs that would maximize information extracted per reading. Optimization of reading selection is also very important, as many possible combinations of readings have high geometric factors and tend to introduce significant noise into the data set. Wilkinson et al (2008) showed that some cross-boreholes arrays are highly sensitive to slight positioning errors. Hence, the optimized arrays will exclude unstable arrays that are highly sensitive to geometric errors and those that have high geometric factors.

The selection of optimal sets of readings for MERIT arrays is created using the modified version of the "Compare R" method of Loke et al (2014b) with algorithms suitable to these new electrode arrangements and is described in Loke et al. (2015). The optimization algorithm works by efficiently selecting a predetermined number of stable arrays that will maximize the model resolution from a myriad of possible array combinations of which there are $\mathrm{N}(\mathrm{N}-1)(\mathrm{N}-2)(\mathrm{N}-3) / 8$ non-equivalent four electrode configurations for $\mathrm{N}$ electrodes when reciprocity is taken into account (Xu \& Noel, 1991; 
Wilkinson et al, 2006b). The model resolution matrix $\mathbf{R}$ measures how well the resistivity of each model cell can be estimated from the observed data (Menke, 1984).

The model resolution matrix $\mathbf{R}$ is calculated from Jacobian (sensitivity) matrix $\mathbf{G}$. G describes the sensitivity of the observations to the resistivities of each model cell. $G_{i j}=\frac{\partial f_{i}}{\partial \theta_{j}}$. , where $f_{i}=$ the ith model response and $\theta_{j}=$ the jth model parameter. In common $2 \mathrm{D}$ resistivity inversions, $\mathbf{G}$ is used in the linearized least-squares equation as

$$
\left(\mathbf{G}^{\mathrm{T}} \mathbf{G}+\lambda \mathbf{C}\right) \Delta \mathbf{r}_{\mathrm{i}}=\mathbf{G}^{\mathrm{T}} \mathbf{d}-\lambda \mathbf{C} \mathbf{r}_{\mathrm{i}-1},
$$

where $\Delta \mathbf{r}_{\mathbf{i}}=\mathbf{r}_{\mathbf{i}}-\mathbf{r}_{\mathbf{i}-\mathbf{1}}$ with $\Delta \mathbf{r}_{\mathbf{i}}$ represents the model parameter change vector between consecutive iterations. $\mathrm{C}$ is the roughness filter constraint, $\lambda$ is the damping factor and $\mathbf{d}$ is the data misfit vector.

The model resolution matrix is then given by

$$
\mathbf{R}=\mathbf{B} \mathbf{A}
$$

where $\mathbf{A}=\mathbf{G}^{\mathbf{T}} \mathbf{G}$ and $\mathbf{B}=\left(\mathbf{G}^{\mathbf{T}} \mathbf{G}+\lambda \mathbf{C}\right)^{-1}$ and the main diagonal elements of $\mathbf{R}$ are used to estimate the model cell's resolution.

\subsection{Forward models and Inversion}

Forward models are simulated using Res2Dmod and Res3Dmod from Geotomo Software. The outputs from both the 2D and 3D forward models are inverted using a modified version of Res2Dinv software, also from Geotomo Software. 2\% Gaussian noise (Press et al., 2007) is added to the synthetic reading before inversion. The modification of Res2Dinv from the commercially available version permits the user to locally increase the smoothing factor in the vicinity of the buried electrodes. This modification has proven necessary to dampen inversion artefacts that otherwise are amplified close to buried electrode locations (Loke et al., 2015). Even after using geometric factor cutoffs for optimized sets of readings, inversions of field data sets with subsurface electrodes tend to have more noise and negative data points compared to conventional arrays (Wilkinson et al., 2008; Loke et al., 2014a). In order to suppress this effect, the inversion is done using the L1-norm constraint in Res2Dinv (Loke et al., 2003). L1 norm constrained inversion has higher stability and lower susceptibility to noise (Liu et al., 2015).

\section{Synthetic Models}

The potential advantages of the MERIT technique over conventional surface resistivity are first assessed by considering simple hypothetical subsurface features. We compare MERIT and surface arrays in two ways: first, arrays with equal total number of electrodes; and second, arrays with equal electrode spacing. 
To compare conventional and MERIT approaches, 2D synthetic models containing several cylinders (radius $=2 \mathrm{~m}$ ) oriented perpendicular to the survey line are generated (Figure $3 \mathrm{a}$ ). The models are designed to illustrate the effective depth of investigation, survey sensitivity, and resolution of both the dimension and the resistivity of the target cylinders. Models for surface surveys assume a conventional dipole-dipole array geometry $(a=3$ and $n=6)$ with 203 measurements. The MERIT models employ an optimized set 1203 of readings generated via the method of Loke et al.( 2015). All models assume a $52 \mathrm{~m}$ long electrode array with $2 \mathrm{~m}$ electrode spacing. The buried electrodes in MERIT models are at $8 \mathrm{~m}$ depth. $1000 \Omega \mathrm{m}$ resistive cylinders are embedded in a uniform $500 \Omega \mathrm{m}$ background. Cylinder center depths range from 3 to $12.5 \mathrm{~m}$.

251
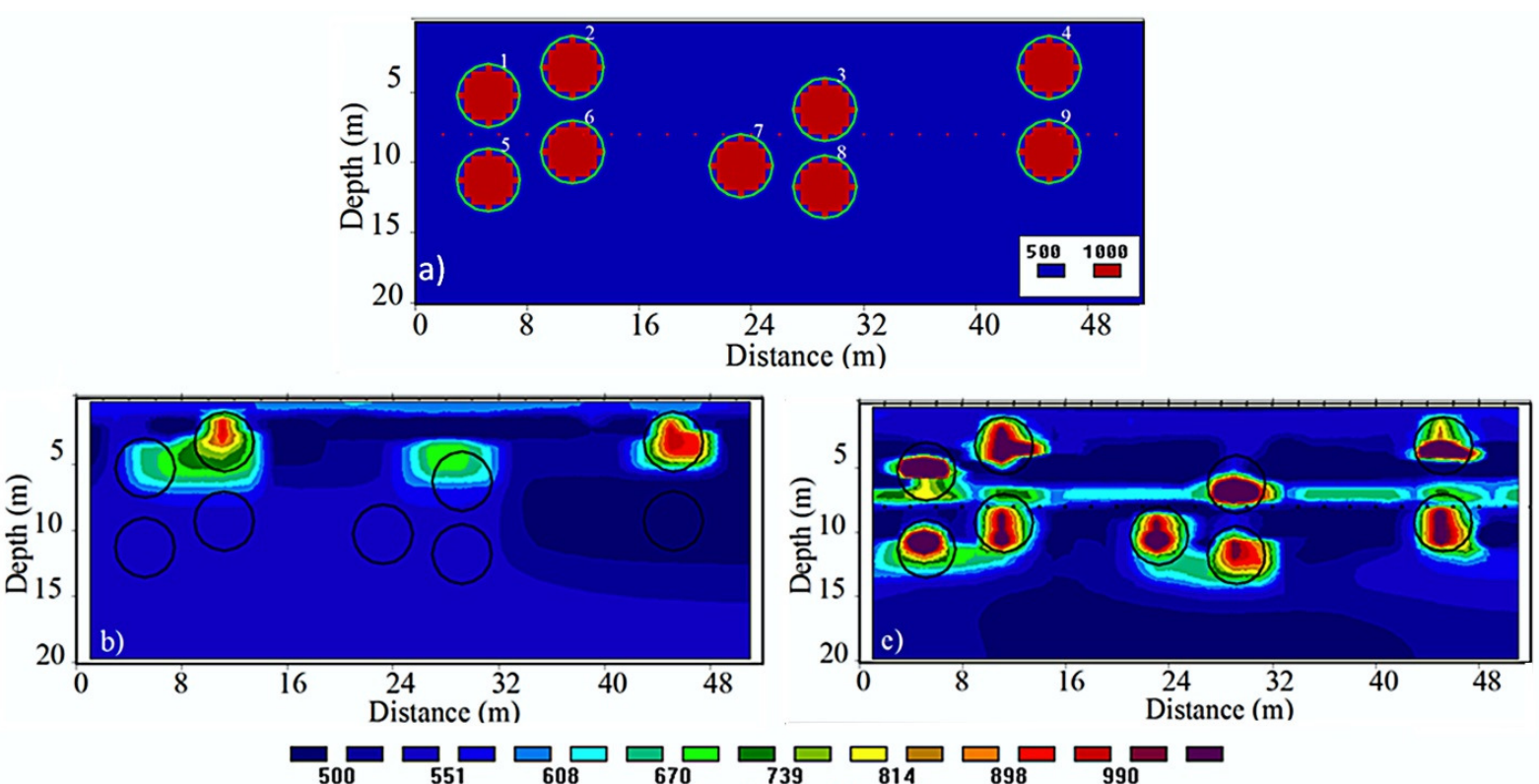

551
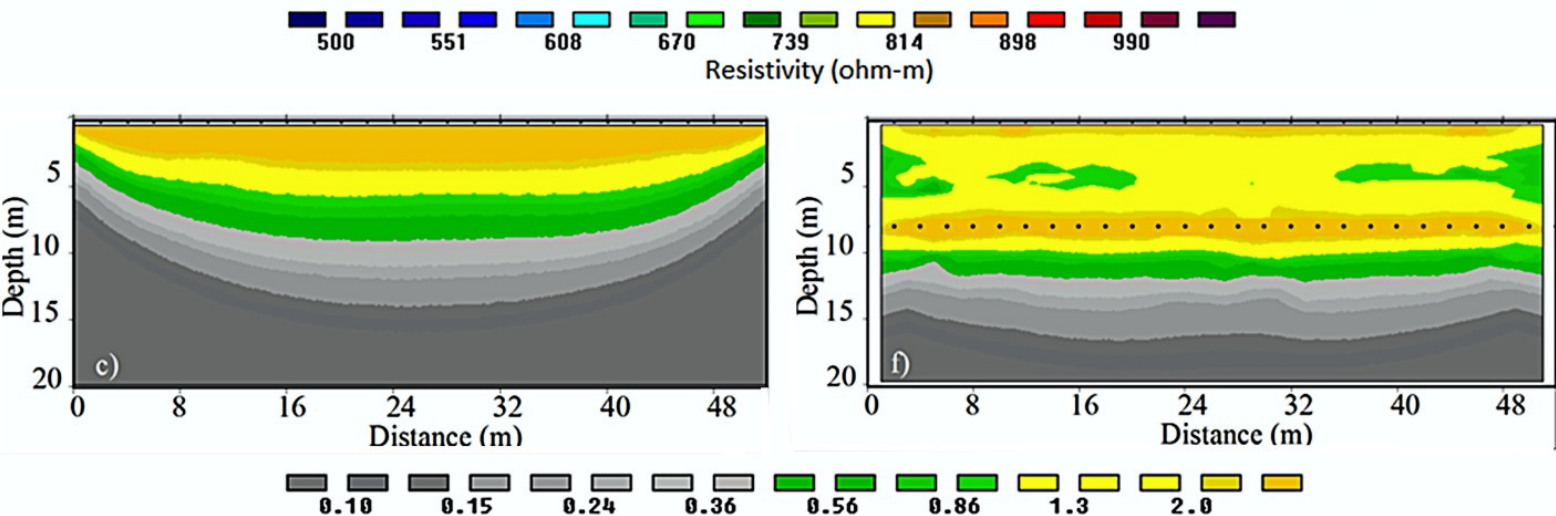

$\square .56$ 


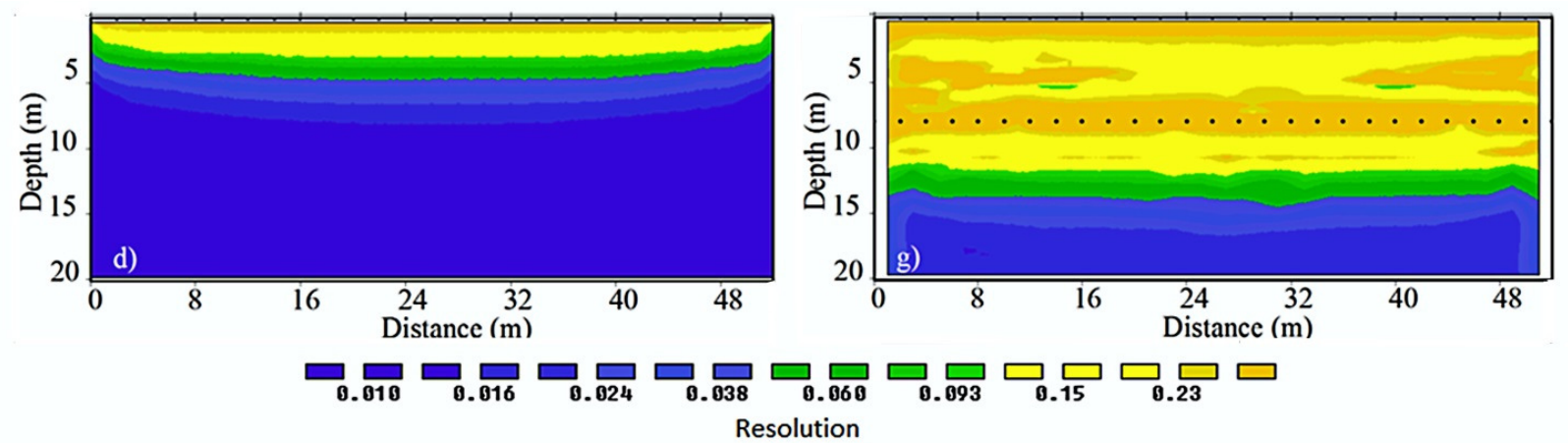

Figure 3. Comparison of surface (left column) and MERIT arrays (right column) over buried cylinders. (a) Forward model showing the locations and sizes of resistive cylinders $(\rho=1000 \Omega \mathrm{m}$, red) embedded in a uniform background $(\rho=500 \Omega \mathrm{m}$, blue). The numbers near the circles are used to label the cylinders. These cylinders are placed at locations of $(5,5.5),(11,3),(29,6.5),(45,3),(5,11.5)$, $(11,9.5),(23,10.5),(29,12.5)$ and $(45,9.5)$ meters across the array and meters deep respectively. Left column: results for surface dipole-dipole array with $2 \mathrm{~m}$ electrode spacing and 203 total readings Right column: results for optimized MERIT array with similar 2m spacing and 1203 total readings. (b) and (e) inversion results with data misfit of $1.2 \%$ and $2.2 \%$ respectively. (c) and (f) show sensitivity (d) and $(\mathrm{g})$ show resolution.

The differences between surface and MERIT surveys are shown clearly in the inversions for the buried cylinders (Figures $3 \mathrm{~b}$ and e). The MERIT array detects the 5 deeper cylinders, which are not resolved in the surface-only array. Moreover, although the surface resistivity is able to detect Cylinder \#3 just above the deeper electrodes, the MERIT array achieves better resolution of both shape and amplitude of the anomaly. Targets like Cylinder \#1 near the profile edges are not properly detected in the surface survey, even when at shallow depth (Figure 3b). This problem is ameliorated with the MERIT array (Figure 3e). Figure 3e shows that while the MERIT array significantly improves resolution of deep targets, it also suffers from inversion artefacts at depths just above the buried array. These inversion artefacts are addressed further below.

The improvement in the overall resolution and sensitivity at depth and near the edges with MERIT is also clearly illustrated in plots of model resolution and sensitivity for the inhomogeneous model (Figure $3 \mathrm{f}$ and g). Following the suggestion of Stummer et al. (2004) to define the depth of low resolution where model cells' $\mathrm{R}$ drops below 0.05 , the depth of low resolution of the conventional surface array is $\sim 5 \mathrm{~m}$. With the MERIT array, this depth of low resolution is pushed to $\sim 5 \mathrm{~m}$ below the buried electrodes, for a total depth of $\sim 13 \mathrm{~m}$. Maps of resolution (Figure $3 \mathrm{~d}$ and $\mathrm{g}$ ) show the conventional surface array is less sensitive to features located near the edges of the survey line. A similar effect is observed in MERIT arrays below the deep electrodes, but between the surface and buried arrays there is good resolution to the ends of the profile (Figure $3 \mathrm{~g}$ ). 


\subsection{Effect of a shallow conductive layer}

The benefits of buried electrodes can be even more striking in the presence of shallow conductive layers. Getting good penetration of electric current into underlying strata (for example limestone beneath clay in covered karst) is difficult as most of the current tends to flow through the conductive layer (Dahlin, 2001). Figure 4a shows the same 2D buried cylinders model as Figure 4a, with the addition of a shallow relatively more conductive $(50 \Omega \mathrm{m})$ layer between 1.5 and $3.5 \mathrm{~m}$ depth.

The addition of this more conductive layer reduces the threshold depth of resolution of the conventional array from $\sim 5 \mathrm{~m}$ to $\sim 4 \mathrm{~m}$ (Figure $3 \mathrm{~d}$ and $4 \mathrm{~d}$ ). The mid-depth cylinder \#3, below the conductive layer, is not detected by the surface array (Figures $4 b, c, d$, ). Yet the $13 \mathrm{~m}$ depth of resolution of the MERIT array is relatively unaffected by the clay layer. Very similar resolution of cylinders is obtained in the presence and absence of the conductive layer (Figure $3 \mathrm{~g}$ and $4 \mathrm{~g}$ ).
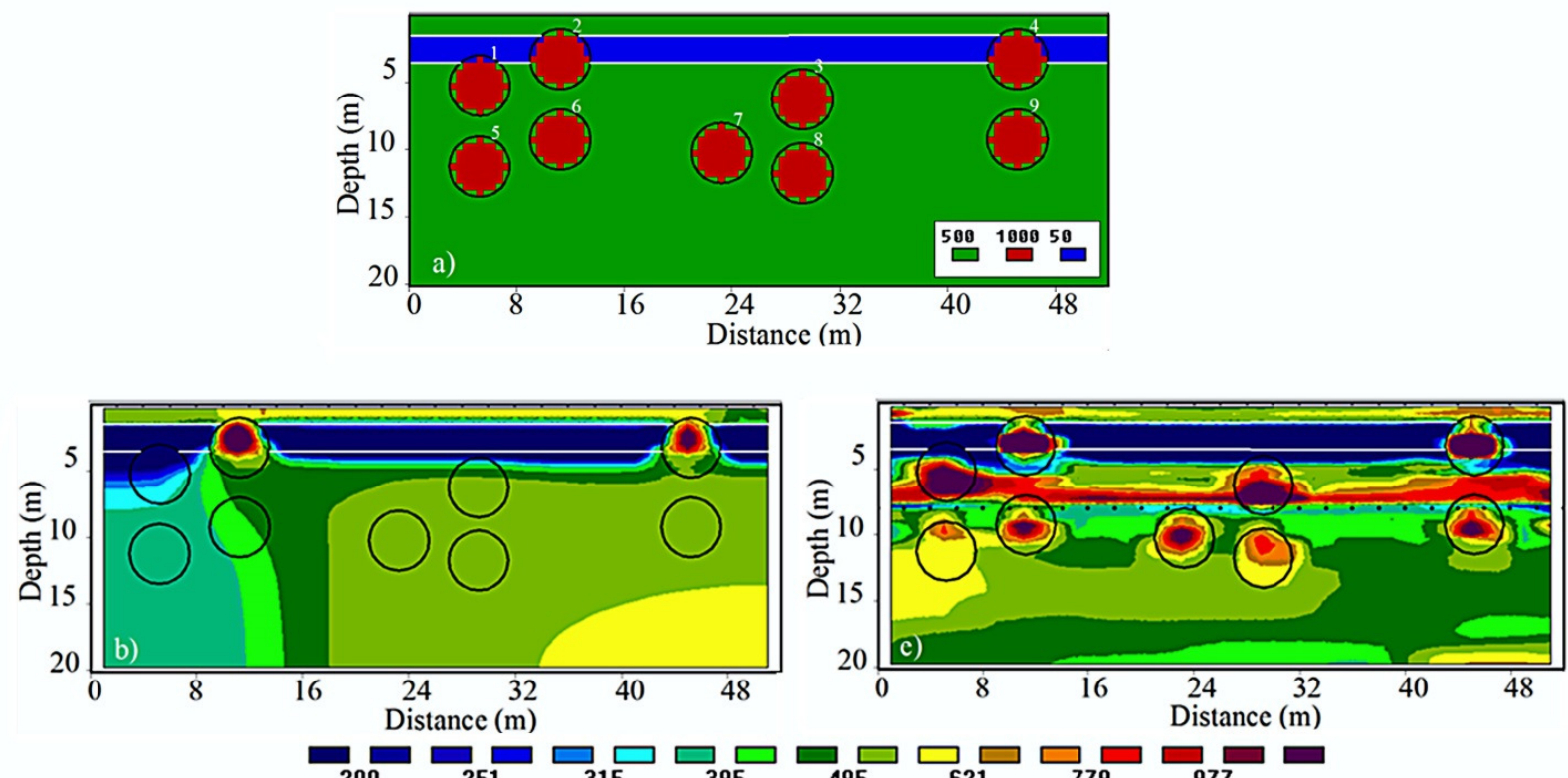

Resistivity (ohm-m)
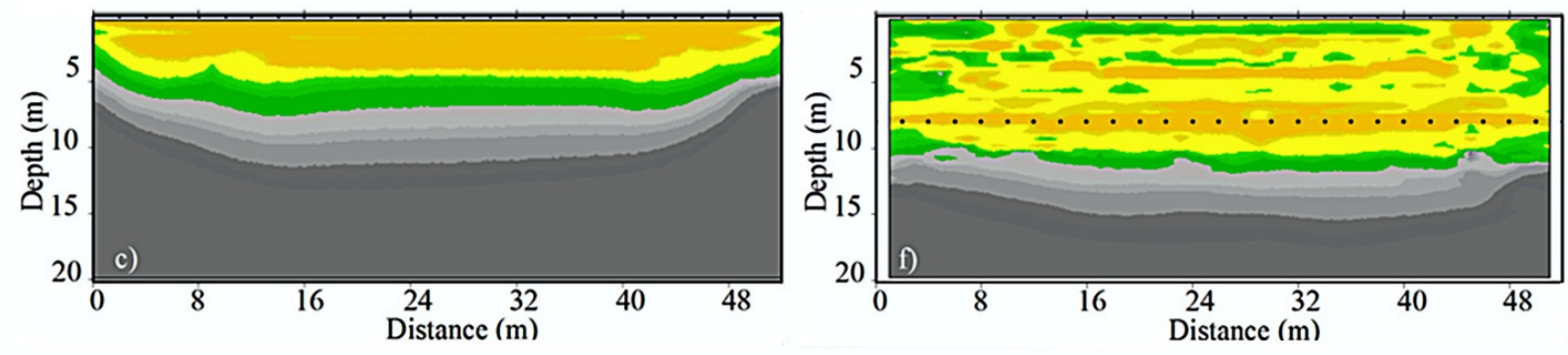

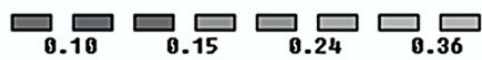




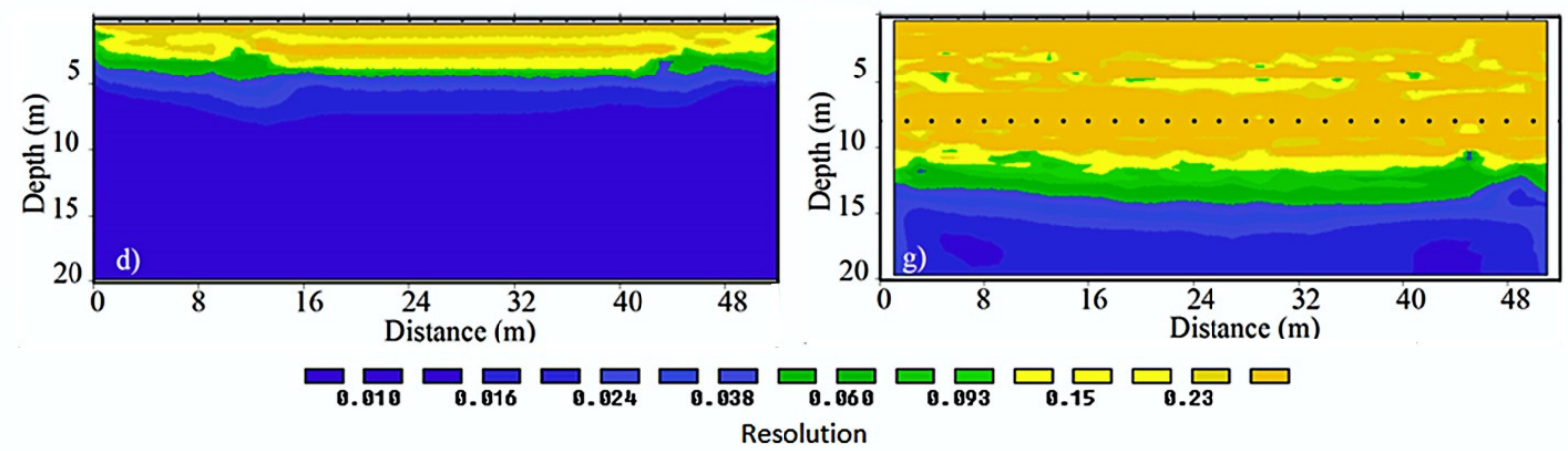

295

296

297

298

299

300

301

302

303

304

305

306

307

308

309

310

311

312

313

314

315

Figure 4. Comparison of surface (left column) and MERIT (right column) arrays over buried cylinders within and below a thin clay layer. (a) Forward model showing the locations and sizes of resistive cylinders $(\rho=1000 \Omega \mathrm{m}$, red) embedded in a background $(\rho=500 \Omega \mathrm{m}$, green) with a shallow low resistivity layer $(\rho=50 \Omega \mathrm{m}$, blue). The numbers near the circles are used to label the cylinders. Cylinder locations as in Figure 3. Left column: results for surface dipole-dipole array with $2 \mathrm{~m}$ electrode spacing and 203 total readings Right column: results for optimized MERIT array with similar $2 \mathrm{~m}$ spacing and 1203 total readings. (b) and (e) inversion results with data misfit of $5.3 \%$ and $8.4 \%$ respectively. (c) and (f) show sensitivity (d) and (g) show resolution.

\subsection{Sinkhole structure}

Figures $2 \mathrm{c}$ and $2 \mathrm{~d}$ show a sinkhole structure observed in west-central Florida. Figure 5 illustrates a synthetic model mimicking simple aspects of this structure. An uppermost sand layer $(1500 \Omega \mathrm{m})$ is underlain by a clay layer $(50 \Omega \mathrm{m})$, in turn underlain by a thick limestone $(500 \Omega \mathrm{m})$ with a thin transitional weathered layer $(100 \Omega \mathrm{m})$ (Figure 5a). The sediment-bedrock interface is disrupted at the center below a sub-surface depression in the sand and clay layers. Finally, the vertical feature cutting the clay layer is filled by sands raveling downward from the top layer. At this field site we infer that these raveling zones can be laterally elongated (Kruse, 2014) or can have small lateral extent with cylindrical conduit-like shapes (Kruse et al., 2006). Both scenarios are investigated, with a 2D model to simulate an elongated raveling zone, and a 3D model for a cylindrical conduit. As a conduit can have hydrologic significance as a breach in the clay semi-confining unit, resolution of this feature is a desired outcome. The conventional arrays comprise 27 surface electrodes spaced at $2 \mathrm{~m}$ spacing while the MERIT arrays comprise 14 surface and 14 deep electrodes with $4 \mathrm{~m}$ spacing thus fixing the total number of electrodes used in both methods close to 28 electrodes.

The resulting inverted images for 2D arrays are shown in Figures 5b,c,e, and f. Comparing the model resolution for the conventional arrays and MERIT shows that the depth of low resolution $(\mathrm{R}<0.05)$ is located at $5.5 \mathrm{~m}$ and $12.5 \mathrm{~m}$ for the $2 \mathrm{D}$ forward model and at $6.5 \mathrm{~m}$ and $13.8 \mathrm{~m}$ for the $3 \mathrm{D}$ forward model, with surface and MERIT arrays, respectively. A noticeable decrease in model resolution is present at the center of the conventional array, due to the central resistive conduit. As seen for the cylinder models, resolution significantly decreases near the edges of the conventional arrays, but not for the MERIT array. 

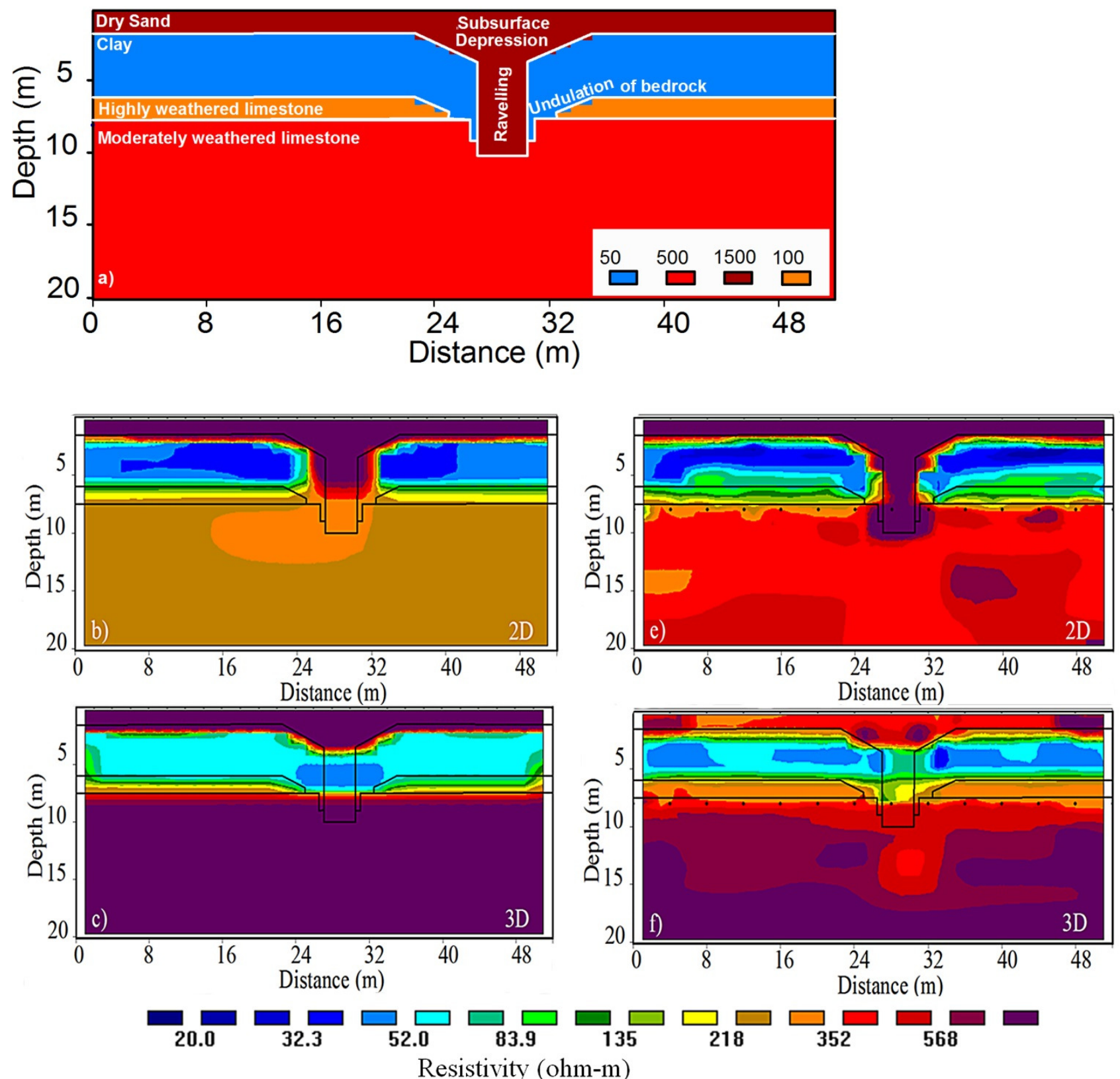

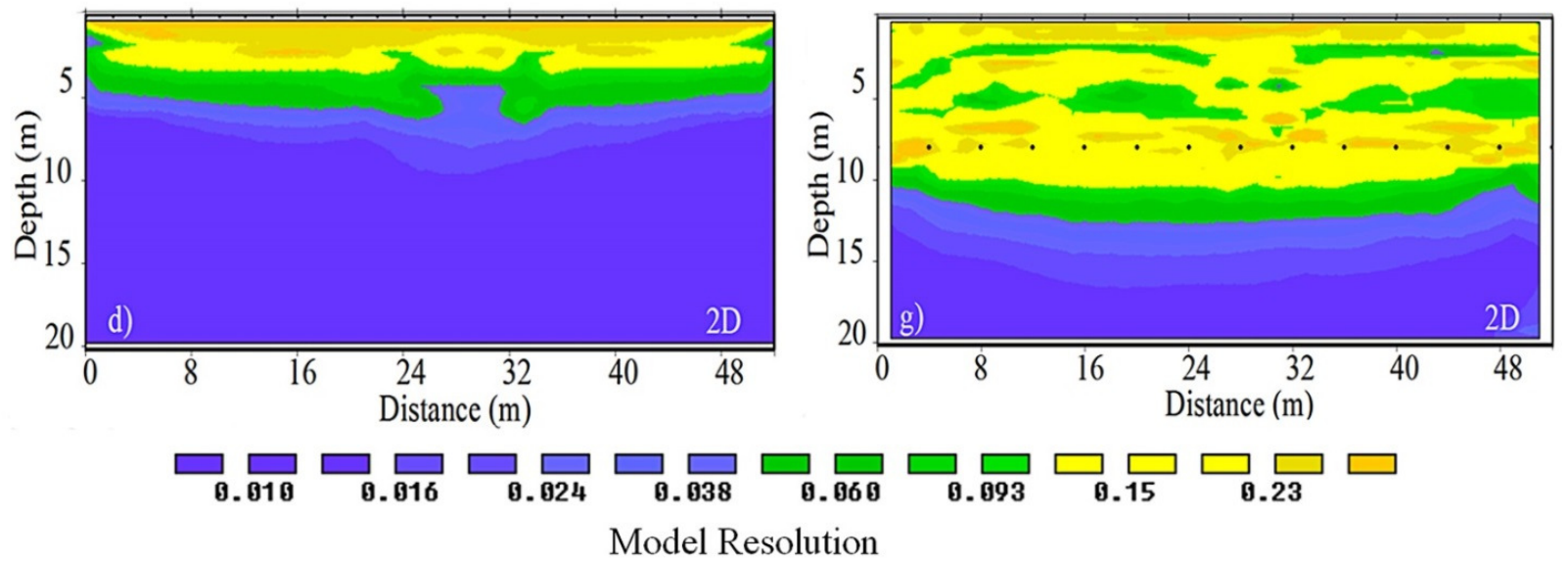

Figure 5 Sinkhole structure. (a) Generalized synthetic sinkhole model showing resistivity variation in a sinkhole structure based on the geologic cross-section by Stwart and Parker,1992. Sand unit ( $\rho=1500 \Omega \mathrm{m}$, green) is on the top and inside a ravelling vertical conduit system. Below the sand is a clay layer $(\rho=50 \Omega \mathrm{m}$, blue) with both the top and bottom contacts undulating. Weathered, clay rich limestone $(\rho=100 \Omega \mathrm{m}$, orange) overlies the bottom fractured limestone ( $\rho=5000 \Omega \mathrm{m}$, light blue). Left column: results for surface dipole-dipole array with $2 \mathrm{~m}$ electrode spacing and 203 total readings Right column: results for optimized MERIT array with similar $2 \mathrm{~m}$ spacing and 1203 total readings. The 2D inversion results are labeled as $2 \mathrm{D}$ or $3 \mathrm{D}$ depending weather the readings are taken from $2 \mathrm{D}$ or $3 \mathrm{D}$ forward models. (b) and (e) 2D inversion of 2D forward model with data misfit of $2.6 \%$ and $2.8 \%$ respectively. (c) and (f) $2 \mathrm{D}$ inversion of 3D forward model with data misfit of $0.8 \%$ and $6 \%$ respectively. (d) and (g) Model resolution for 2D inversion of 2D forward model.

Figure 5 shows that both surface and MERIT methods are clearly able to detect the shallow contact and sub-surface depression between the top sand and clay layers. The inversion of the readings taken from the 3D forward model shows that this undulation is slightly less resolved in the MERIT array since the top electrodes have $4 \mathrm{~m}$ spacing, compared to the conventional array which has $2 \mathrm{~m}$ spacing. More significant differences are revealed in the identification of the vertical raveling zone. This raveling zone is manifested as a break in the continuity of the clay layer between $27 \mathrm{~m}$ and $32 \mathrm{~m}$ and a sharp increase in resistivity compared to the resistivity of the clay layer (50 ohm-m). With the traditional surface array, the 2D conduit (elongate raveling zone) (Figure 5b) is better resolved than the 3D conduit (cylindrical raveling zone) (Figure 5c), in the sense that there is no indication of the raveling zone penetrating the limestone for the 3D cylindrical conduit. With the MERIT surveys, both the $2 \mathrm{D}$ and $3 \mathrm{D}$ versions of conduit are detected in the form of anomalies at limestone depths (Figures 5e and f). However, the 3D cylindrical conduit (Figure 5f) is clearly less accurately captured in the inversion. MERIT's improvement over the surface array in resolving the $3 \mathrm{D}$ cylindrical conduit and its vertical continuity is novel and important in terms of helping to link the surface features with activities in the intermediate (overburden soil) and deeper (bedrock) activities. These linkages are keys to understanding hydrologic function and to properly mitigate karst-related sinkhole hazards. 
355

Cavities in the limestone bedrock are themselves important targets. If the voids can be imaged, grouting can be done much more efficiently to mitigate the collapse of overlying sediments. Figure 6 shows a model with a top sand soil underlain by a clay layer that is in turn underlain by limestone. In
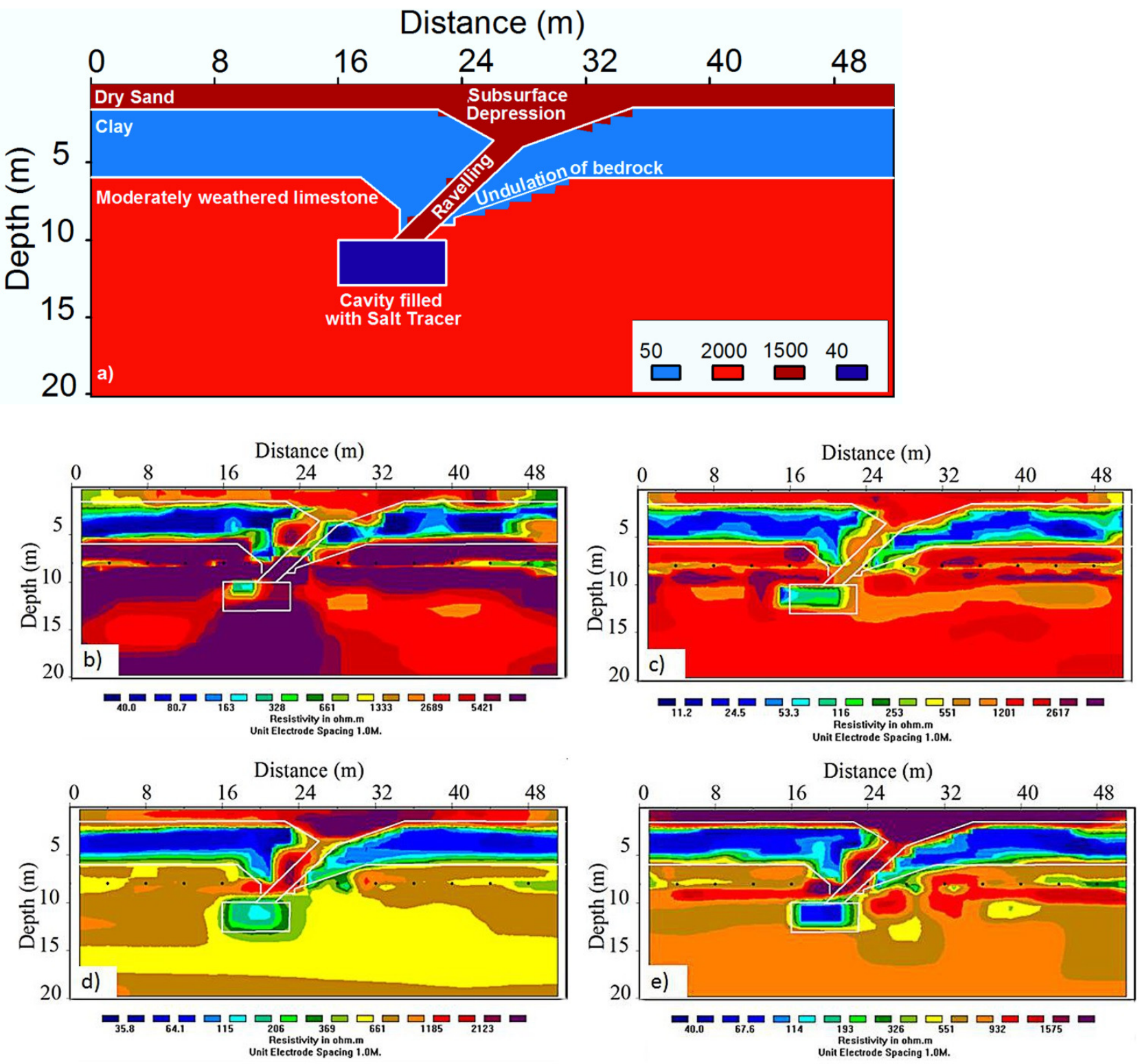

Figure 6. Comparison of Data misfit with different bedrock resistivities. (a) Resistivity structure of Forward model. (b) Inverted resistivity image of highly resistive $(\rho=12000 \Omega \mathrm{m})$ bedrock with data misfit of $18.7 \%$ at iteration 8 (c) Inverted resistivity image of moderatly resistive $(\rho=2000 \Omega \mathrm{m})$ bedrock with data misfit of $4.3 \%$ at iteration 8 . (d) Inverted resistivity image of low resistive ( $\rho=400 \Omega \mathrm{m}$ ) bedrock with data misfit of $7.3 \%$ at Iteration 4 . (e) Inverted resistivity image of low resistive $(\rho=400 \Omega \mathrm{m})$ bedrock with data misfit of $1.2 \%$ at Iteration 10 . Note that unlike the other figures in the paper, the color scale of resistivity varies from image to image. 
this model the sub-surface depression of the sand-clay contact is laterally offset from a deep dissolution cavity. The cavity is the original source of hazard. Ideally, mapping of the raveling zone and shallow and deeper undulations could help in estimating the location of the associated limestone cavities. One way researchers have tried to map analogous sub-surface geological heterogeneities is through the injection of conductive tracers (e.g. Slater et al., 1997; Slater et al., 2000; Robinson et al., 2015). These conductive tracers are expected to follow preferential flow paths, such as the raveling zone. For resistivity surveys, the conductive tracers can preferentially enhance signal contrast, and 'light up' an area in time-lapse imaging. Here we examine such a scenario, simulating a void filled with conductive tracer.

In the 2D model in Figure 6a the conductive fluid is assumed to be concentrated in a cavity, while the overlying raveling zone has returned to background high resistivity. Figure $6 \mathrm{~b}-\mathrm{d}$ show inversion results for the same structure, with varying resistivity of the limestone bedrock (high=12000 $\Omega \mathrm{m}$, medium=2000 $\Omega \mathrm{m}$ and low=400 $\Omega \mathrm{m}$ ). Also the bedrocks in all the models has good signal contrast compared to the overlying clay and the saline filled cavity. In all cases the MERIT array captures the sand depression, the low-resistivity cavity, and some anomaly in the vicinity of the raveling zone. All inversions show artefacts near the depth of the buried electrodes, which appear as the horizontal 'stripes' around the deep array. And because the method yields artefacts close to the buried electrodes, electrodes should ideally be buried above or below target depths - perhaps a distance on the order of the lateral spacing between electrodes.

\subsection{Data RMS misfit: survey design and interpretation}

The misfit between the data and the inversion results (presented as a percentage of the reading) is a commonly used gauge of the quality of the inversion results. Data misfits for MERIT surveys are typically higher than for surface surveys, as discussed in the introduction. In Figures $6 \mathrm{~b}, 6 \mathrm{c}$, and $6 \mathrm{e}$ the inversions were run until the criteria for termination was satisfied. The criterion assumed in this paper is that the results of an inversion iteration vary by less than $0.1 \%$ from the previous iteration. At termination, the data misfits are $18.7 \%, 4.3 \%$ and $1.2 \%$ for the high, medium and low resistivity bedrock models respectively. Interestingly, the quality of the inversion is highly dependent on the presence of a highly resistive unit and absolute value of the resistivity contrast between the conductive clay and the resistive limestone. The higher the bedrock resistivity, the higher the data misfit and the poorer the recovery of the raveling zone and the void. Also more artifacts with locally high or low resistivity values are introduced as seen in the model with the highest resistivity value and data misfit of $18.7 \%$. Presumably this is because of:1) the ease of current flow in the less resistivity bedrock models which allows better imaging of the void and 2) the negative effect of very high apparent resistivity values on the inversion. These high apparent resistivity values arise from array geometries that sample larger volume of the highly resistive bedrock. In L1-norm regularized inversion, these high resistivity readings would be more affected by the damping contributing to the bigger data misfit. This is an important factor since in most geological settings; the presence of more indurated, drier, resistive bedrock underlying softer, moister, less resistive sediment is a common state. Thus the deep arrays of MERIT, closer to the bedrock, tend to have higher data misfit. 
Figures $6 \mathrm{~d}$ and 6e illustrate the dangers of pushing the inversion process too far to lower the RMS misfit. Both figures share the same forward model; Figure $6 \mathrm{~d}$ shows the inversion terminated at iteration 4 with $7.3 \%$ misfit; Figure $6 e$ at iteration 10 with $1.2 \%$ misfit. The latter is below the $2 \%$ noise level; at this level the inversion is clearly amplifying artefacts as it fits the noise. The geological structures are equally identifiable in both cases.

In summary, the results from MERIT arrays are reasonably expected to have a higher data misfit especially in areas with more complex subsurface heterogeneity that includes highly resistive bedrocks. We suggest that these results should be accepted after a moderate effort to reduce error and an attempt to do ground-truthing and repeated or reciprocal measurements. Similar high data misfit while giving geologically reasonable results is observed in cross-borehole surveys as shown by Wilkinson et al. (2008) and Loke et al. (2014a).

The data processing approach used in the field studies in this paper to reduce data misfit includes eliminating bad data points in a sequential manner involving inversion and removal of noisy data points. In the inversion, reciprocal measurements are used to suppress noisy data using a data weighting matrix.

\section{Laboratory Experiments}

Two laboratory experiments were carried out to investigate the effectiveness of MERIT in a controlled environment. Both experiments were designed to be slightly similar to the synthetic models discussed above. In the first experiment (Figure 7), 5 resistive rods were placed in a water tank, creating a scenario similar to the cylinder synthetic model of Figure 3. In a second experiment (Figure 8), a small analogue sinkhole model was created to roughly mimic the sinkhole cross-section of Stewart and Parker, (1992), Figure 2c. In both experiments deep electrodes were implanted directly beneath surface electrodes.

\subsection{Rectangular Rods}

In this experiment, 5 small insulated prisms were fixed at known locations (Figure 7). Data were collected for a conventional array with 28 electrodes spaced at $1 \mathrm{~cm}$ and a MERIT array with 14 surface and 14 deep electrodes spaced at $2 \mathrm{~cm}$. Deep electrodes were mounted at $5 \mathrm{~cm}$ depth. All rods except 2 and 3 had dimensions of $3.5 \times 3.5 \mathrm{~cm}$ in the plane of the survey and $80 \mathrm{~cm}$ perpendicular to the survey centered in the middle of the rods. Rod 2 and rod 3 had dimensions of $2 \times 4 \times 80 \mathrm{~cm}$ and 6 x 3.5 x $80 \mathrm{~cm}$, respectively (Figure 7). Holes drilled in blocks 2, 4 and 5 served as passages for the deep electrodes. Rods 1 and 5 are located close to the edges of the survey line while the rest are located closer to the center. Rods 2 and 4 mostly lay between surface and deep electrodes, rod 5 is close to the deep electrodes and rods 1 and 3 are located below the deep electrodes.

The surface array detected only the shallow rods 2 and 4 (Figure $7 \mathrm{~b}$ and $7 \mathrm{c}$ ) but poorly resolved the dimension of the smaller rod 2. The MERIT array (Figure 7d) detected the shallow rods 2 and 4 and also better resolved the smaller rod 2. It also detected the deep rod 3 and rod 5 near the edge. Unlike 
the MERIT array, the surface array was not able to detect rod 5 near the edge and above the deep electrodes.
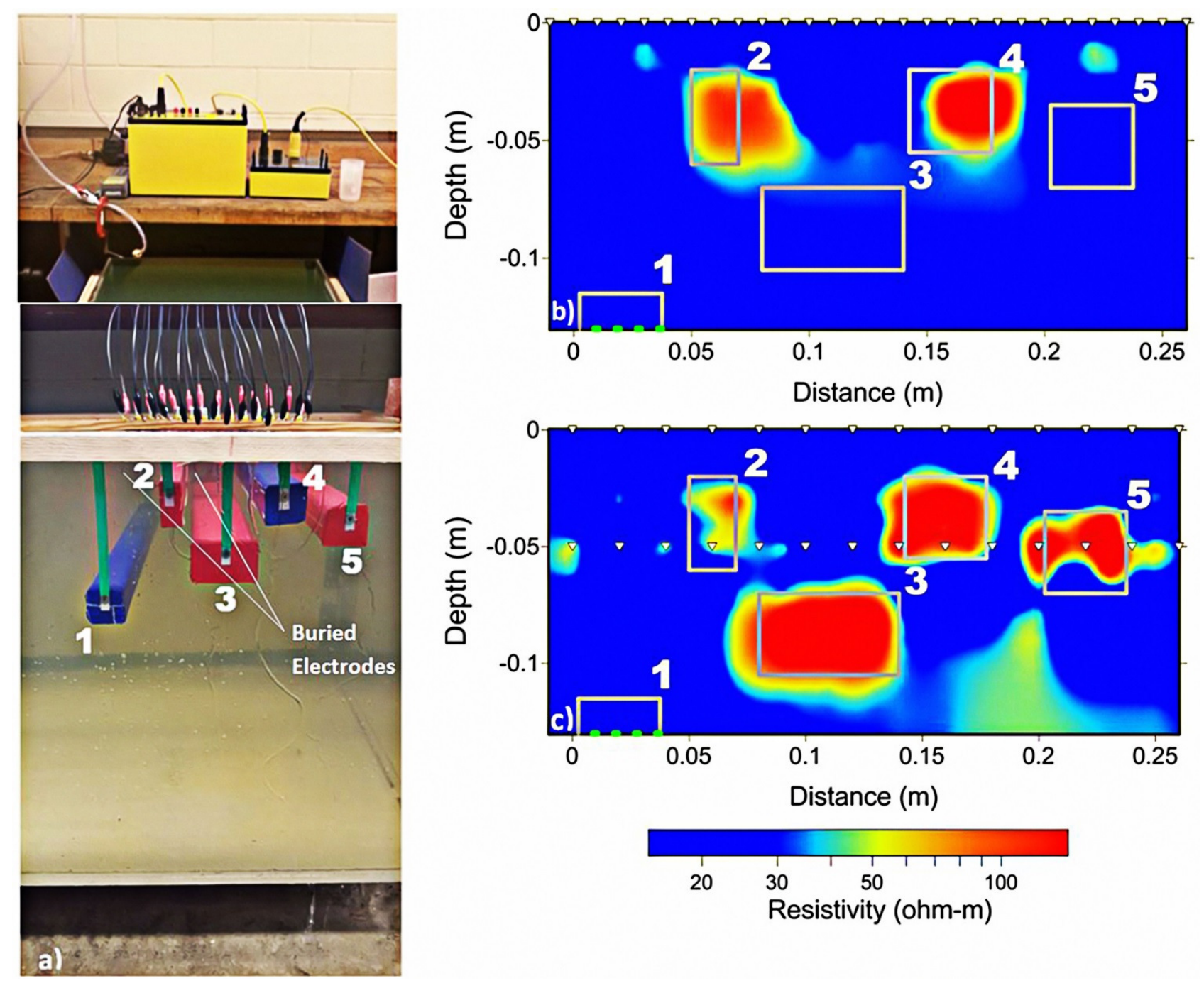

Figure 7. Experimental Rods. (a) Experimental setup of 5 rectangular rods in a water medium. The rods are made of wood insulated by plastic tape. The green dotted lines in rod 1 indicates that only part of rod one is shown in (b) and (c). Resistivity measurements are carried out using a SuperSting R1 resistivity meter. Both the surface and deep electrodes are made of copper wires with insulated and stripped sections. (b) Inverted resistivity image using conventional surface arrays (average noise level $=0.67 \%$, data misfit error $=3.6 \%$ ). (c) Inverted resistivity image using MERIT arrays (average noise level $=0.39 \%$ and data misfit error $=7.5 \%$ ).

The MERIT array suffers a similar limitation below the deep arrays, where rod 1 near the edge is not detected. While the MERIT array has doubled the depth of resolution of the surface array, it suffers 
from inversion artefacts (at depth, right side) and near the deep electrodes. It also slightly mis-located rod 2 which is probably due to its smaller size and the presence of several target prisms to resolve.

\subsection{Sinkhole analog model}

An experimental sinkhole analog model was constructed mimicking a sediment-covered sinkhole structure such as the one studied by Kruse et al. (2006) (Figure 2c). The model has top layer of loose fine to medium sand underlain by cohesive clay soil (Figure 8). Below the clay, in order to mimic the weathered undulations in resistive bedrock, limestone blocks were emplaced over insulated foam padding. Weathered limestone chips mixed with a small amount of clay were used to mimic the weathered top of limestone. Three sand-filled "conduits" were created along the midline of the tank through the sand and clay with $4.5 \mathrm{~cm}$ diameter plastic tubing with sand which was then removed, and the conduit filled with sand. Two conduits are vertical, one is inclined at an angle of $\sim 70$ degrees (Figure 8). In the middle of the tank just below these conduits, construction bricks with limestone chip and sand-filled cavities further simulates the bedrock that has undergone complex dissolution.

Two electrode geometries were tested. The first array (A, Figure 8) had 14 surface electrodes and 14 deep electrodes buried at $8 \mathrm{~cm}$ depth; with $5.08 \mathrm{~cm}$ horizontal spacing between electrodes. The array was centered over a central vertical raveling zone. Clearly resistivity readings will be affected by the edges of the tank (Loke et al, 2014b), but were neglected for the purposes of this simple experiment. The second (B, Figure 8) had 14 surface and 14 deep electrodes buried at $5 \mathrm{~cm}$ depth with a $2.54 \mathrm{~cm}$ horizontal spacing. Array B was centered over the inclined raveling zone far enough (half the survey length) from the tank edges that edge effects should be small.

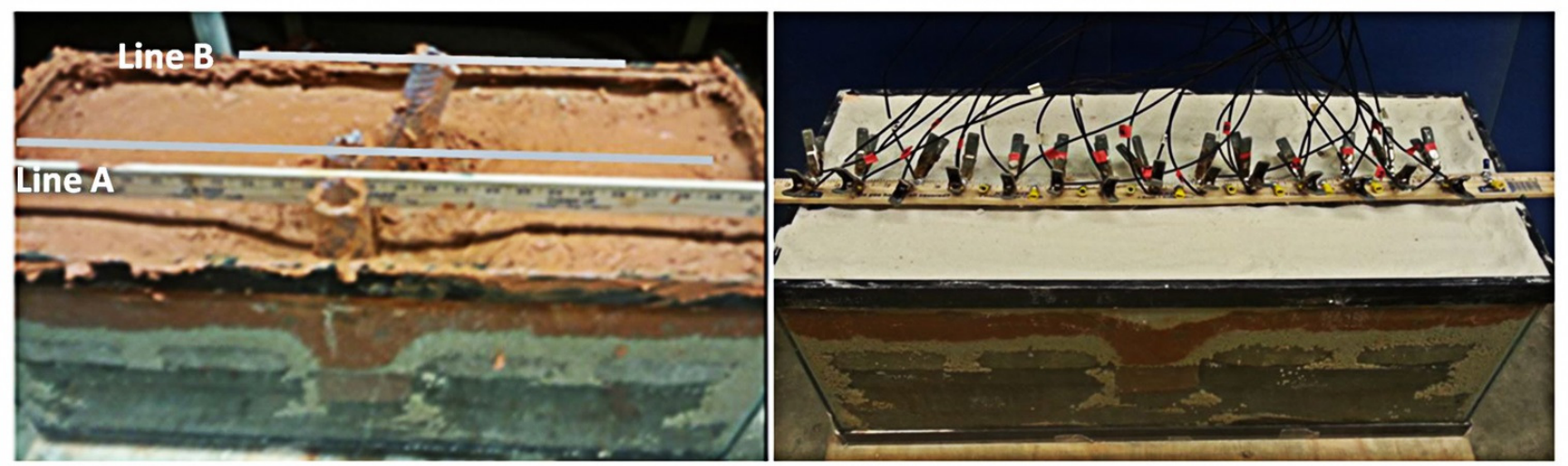

Figure 8. Sinkhole analog model based on the geologic cross-section of a covered karst sinkhole (Stewart and Parker, 1992). (Left) Photo taken during construction. Resistive foam padding lines the tank base. A limestone bedrock with limestone chip and sand-filled vertical fractures is created over the base, and overlaind by fragmented limestone. In the middle, red construction bricks with chip and sand-filled voids simulate a more heterogeneous zone. A clay layer overlies the fragmented limestone and dips down over the bricks. Two vertical conduits and one inclined conduit are created in the clay layer with plastic tubing. The tubing was removed, the conduits filled with sand, and a poorly saturated sand layer was overlain on the top of the clay. The gray lines show the location of the two 
resistivity lines with $2.54 \mathrm{~cm}$ (top) and $5.08 \mathrm{~cm}$ (bottom) electrode spacing. The left edges of the lines correspond to the starting point of the survey lines. (Right) Resistivity setup for the study with $5.08 \mathrm{~cm}$ electrode spacing; 14 at the surface and 14 buried at $8 \mathrm{~cm}$ depth.

Figure 9a shows the inversion results from the experiments. The first figure shows the inversion result from the array A, the longer array with deeper electrodes across a vertical conduit. It can be seen that most of the longer wavelength sinkhole features are well resolved. The sub-surface depression in the sand-clay contact and the top of bedrock are well imaged. Moreover, the narrow vertical raveling zone penetrating the clay layer is also detected. However, the continuation of this zone into the redbrick as sand filled cavity is not properly resolved, presumably due to the smaller resistivity contrast between the sand and the redbrick.

Figure 9b, over an inclined conduit, shows similar results. The effective depth of penetration is lower due to the shorter survey length. Nevertheless both the shallow contact between the sand and clay layer and the contact between the clay and the underlying limestone chips are seen. The inclined sandy conduit is not clearly imaged, but the offset between the lower depression centered at a distance of $0.125 \mathrm{~m}$ and sand-clay contact depression centered at $0.175 \mathrm{~m}$ is slightly captured.

Both inversions show considerable fine scale complexities that are not intentionally included in the physical model. These features could be inversion artifacts or could also be small heterogeneities that arise during material mixing or watering. Although the result captures most of the target features, it has a very high data misfit (14.9\% for Figure 9a and 28.05\% for Figure 9b) that is extremely high compared to the noise in the data set determined from repeated measurements, which is less than $1 \%$ for both experiments. This high data misfit is possibly related to the presence of the highly resistive bedrock layers represented by solid rock blocks and insulated foam padding. These results are fairly consistent with the results from the numerical model (Figure 6b) involving a sinkhole structure with highly resistive bedrock $(12000 \Omega \mathrm{m})$. For Figure $9 \mathrm{~b}$, an attempt made to reduce the data misfit by removing noisy data points resulted in lower misfit but more artefacts with less resemblance to the true analogue model.
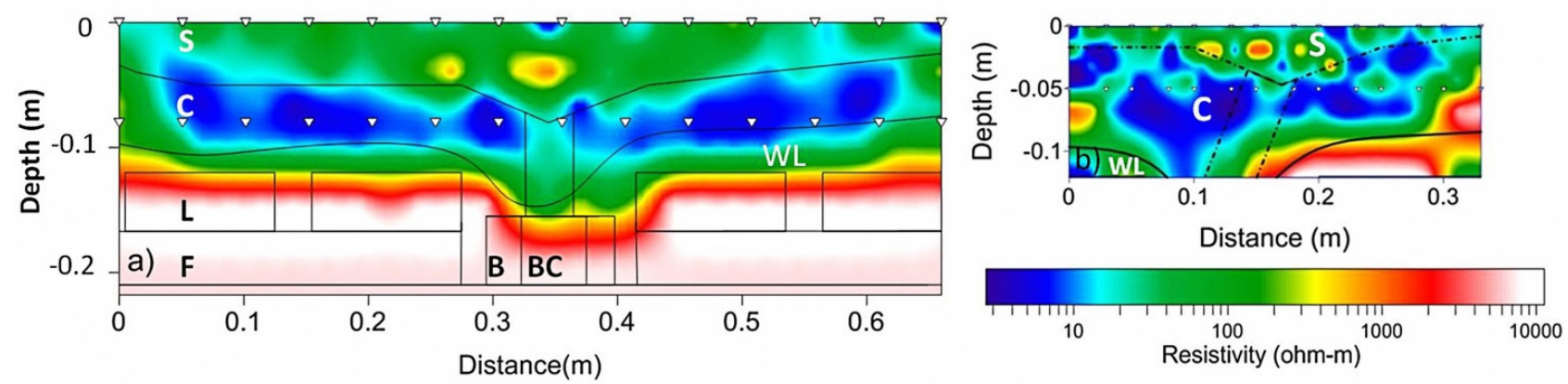

Figure 9. Resistivity inversion results from experimental sinkhole analogue model. (a) Resistivity measurment taken using 28 electrodes and $5.08 \mathrm{~cm}$ spacing and the deep electrodes burried at $8 \mathrm{~cm}$ depth. The line is located at the center of the vertical ravelling zone. A total of 502 measurements are 
used in the inversion. $\mathrm{S}=\mathrm{Sand} ; \mathrm{C}=$ Clay; $\mathrm{L}=$ limestone; $\mathrm{WL}=$ Weathered limestone; $\mathrm{B}=$ brick; $\mathrm{BC}=$ cavity in brick; $\mathrm{F}=$ Foam padding. (b) Resistivity measurement taken using 28 electrodes and $2.54 \mathrm{~cm}$ spacing and the deep electrodes burried at $5 \mathrm{~cm}$ depth. The line is located at the center of the inclined ravelling zone. A total of 579 measurements are used in the inversion.

5. Field case study

Two field-scale case studies are described here.

5.1 Field case study 1: Sinkhole related subsurface karst features

The first case study site is located in covered karst in-west central Florida, in the Geopark research site on the campus of the University of South Florida (Figure 11; location shown in Figure 2). This research site has been studied by Stewart and Parker (1992) and Kruse et al. (2006). Ground truth information includes drilling logs, standard penetration tests (SPT), cone penetration tests (CPT), geologic profiles, and GPR survey data (Figures 11-14).

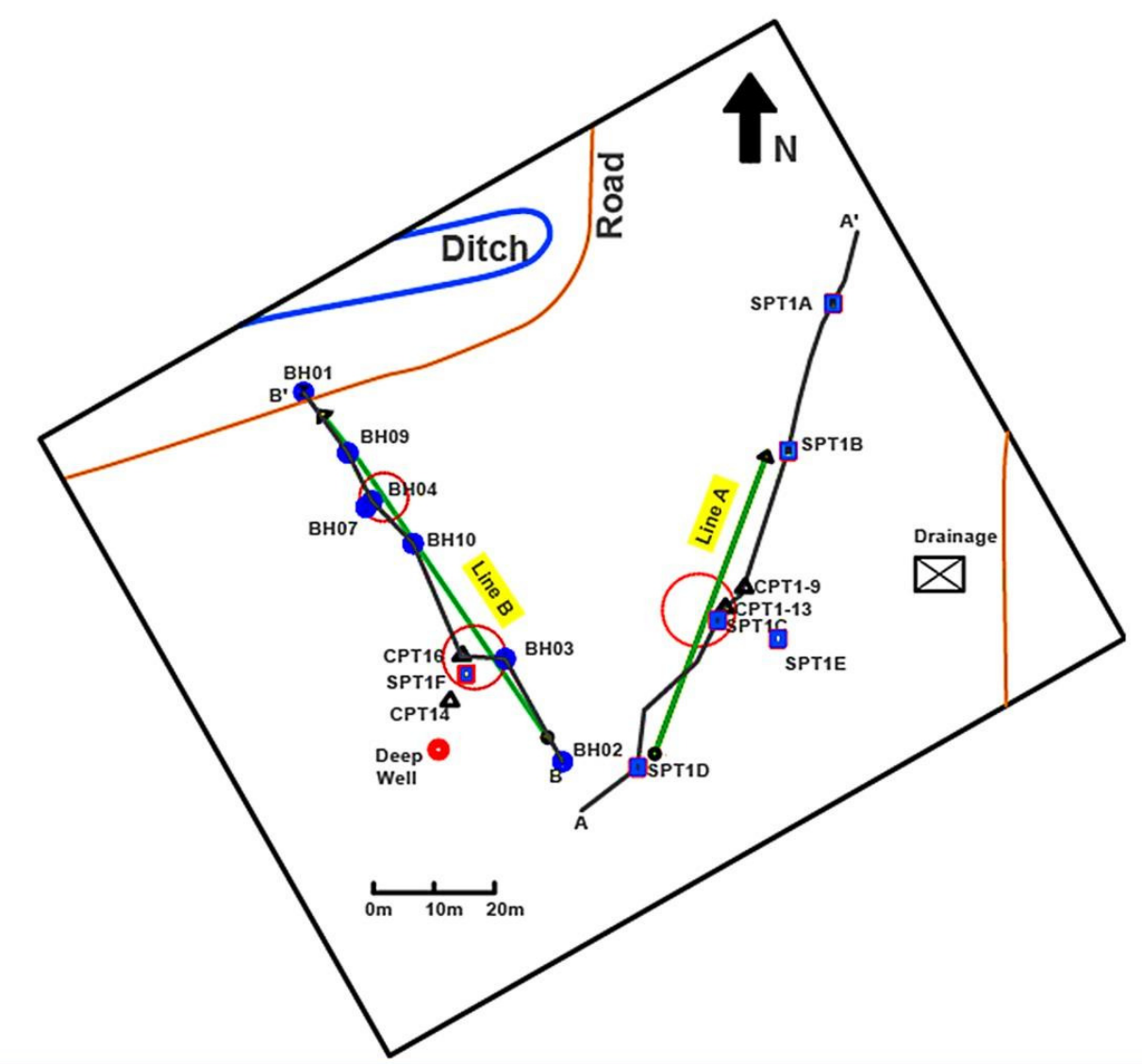

Figure 11. Map of Geopark research site at the University of South Florida, USA. The cyan lines indicate geologic profile lines studied by Stewart and Parker (1992) and present study. The location of this site is the same as for the GPR lines as shown in Figure 2. Resistivity surveys along Lines A and $\mathrm{B}$ are described in this paper. The start of both surveys is towards the bottom end of the lines. 
Two MERIT lines (Line A and Line B) were installed by implanting 14 deep electrodes on each line. The deep electrodes are implanted at $7.6 \mathrm{~m}$ depth with a $4 \mathrm{~m}$ spacing on Line A and at a depth of $5 \mathrm{~m}$ with $5 \mathrm{~m}$ spacing on Line B. Conventional surface resistivity surveys were conducted using a $2 \mathrm{~m}$ spacing on Line A and $2.5 \mathrm{~m}$ and $5 \mathrm{~m}$ spacing for Line B. In both survey lines, the main targets are common sinkhole-related features, including contacts between stratigraphic layers, undulations at contacts, raveling zones and dissolution cavities (e.g. Figure $2 b$ ).

The noise level of the field data can be described in two ways: first, as the percent difference between repeated measurements with the identical electrode locations, and secondly as the percent difference between reciprocal sets of readings, in which the current and potential electrode pairs are switched. (In theory reciprocal readings should produce identical apparent resistivities.) By the first metric (repeated measurements), MERIT arrays have generally higher noise level compared to the surface arrays. On line A the average noise level in the field data are $0.58 \%$ and $2.1 \%$ for the surface and MERIT arrays respectively. On Line B, the same values are $1.6 \%$ and $1.7 \%$. Reciprocal measurements were run for MERIT arrays on Line B; these show a wide range, with a minimum reciprocal error of $0.1 \%$, and $75 \%$ of the reciprocal errors below $7.2 \%$. During the inversion, errors associated with the reciprocal readings were used in the data weighting matrix. The average reciprocal error becomes $3 \%$ after filtering out the $25 \%$ of the data that has a higher reciprocal error above $7.2 \%$.

The addition of the deep implant electrodes results in significant improvement in depth of investigation as characterized by resolution, in both line A and line B (Figure 12). Improvements are most significant in regions that have low resistivities, and on the edges of the array between surface and deep electrode depths.
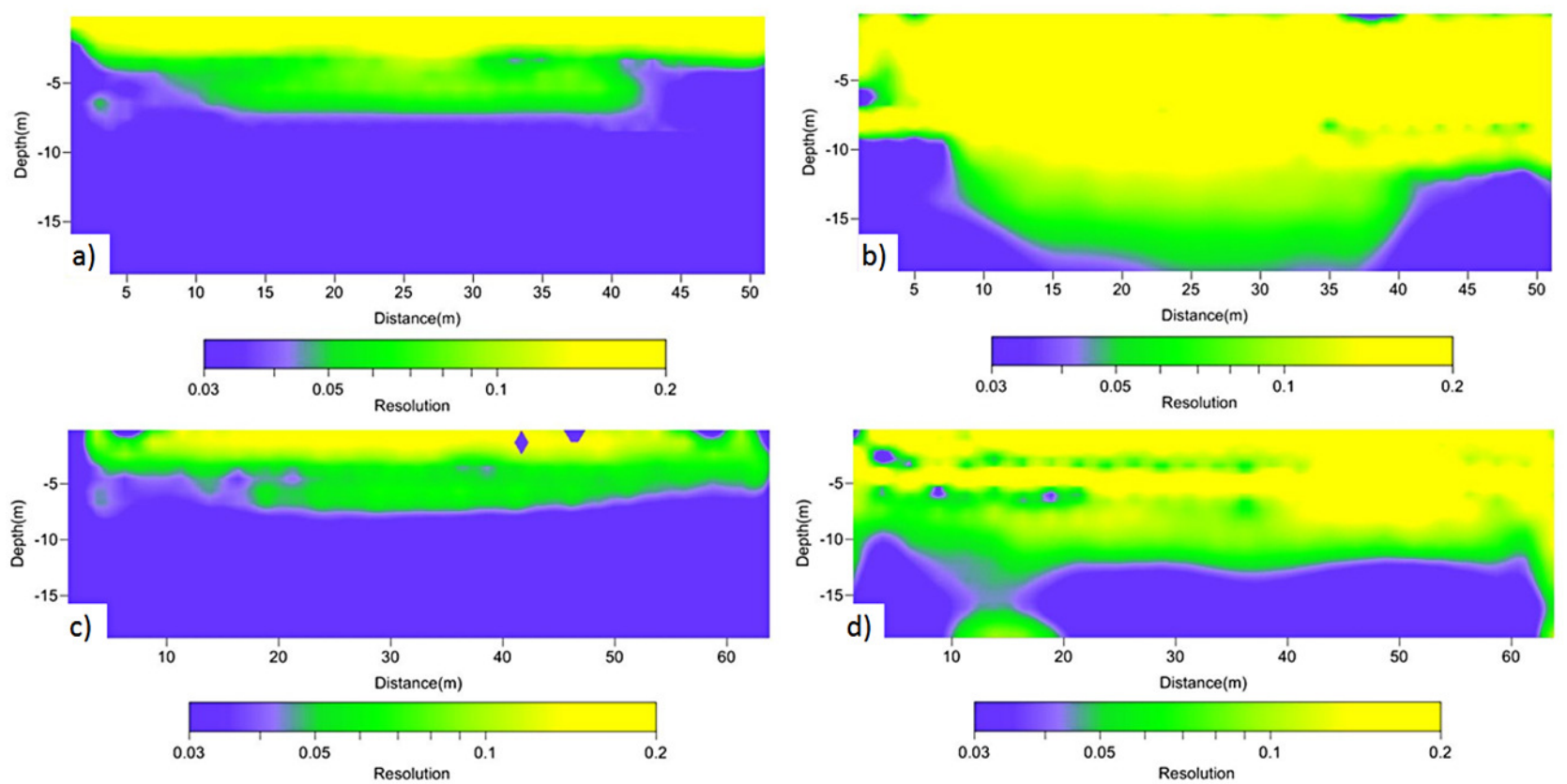
Figure 12. Comparison of resolution of resistivity survey with 28 electrodes arrays across the surface (left graphs) versus 14 shallow and 14 deep electrodes (right graphs) for Line A (top) and Line (B) (bottom). (a) Line A using conventional surface arrangement. (b) Line A using MERIT arrangment with electrodes at $7.6 \mathrm{~m}$ depth. (c) Line B using conventional surface arrangment. (d) Line B using MERIT arrangment with electrodes at $5 \mathrm{~m}$ depth. Both lines run from south on left to north on right. See Figures 2 and 11 for locations.

On both lines, sinkhole-associated features include loose sediments, presumably raveling zones, which have higher moisture content relative to the surrounding less disturbed soils (Figures 13a at 24 and 29 $\mathrm{m}$ and Figure $14 \mathrm{~b}$ at $45 \mathrm{~m}$ ). These raveling zones result in low resistivity areas around the sinkhole locations, especially during the rainy season. On Line A (Figure 13), the use of the deep electrodes enables four distinct improvements in the resistivity image. (1) There is better agreement with a depression in a GPR reflecting horizon identified from simple auger holes as an internal stratification within the top sand layer with a slightly cohesive internal layer of clayey silty sand and coring indications for the sand-clay contact (magenta line Figure 13). (2) The MERIT results show better agreement with the general attitude of bedding captured in the CPTs, SPTs, and wells (Figure 13).
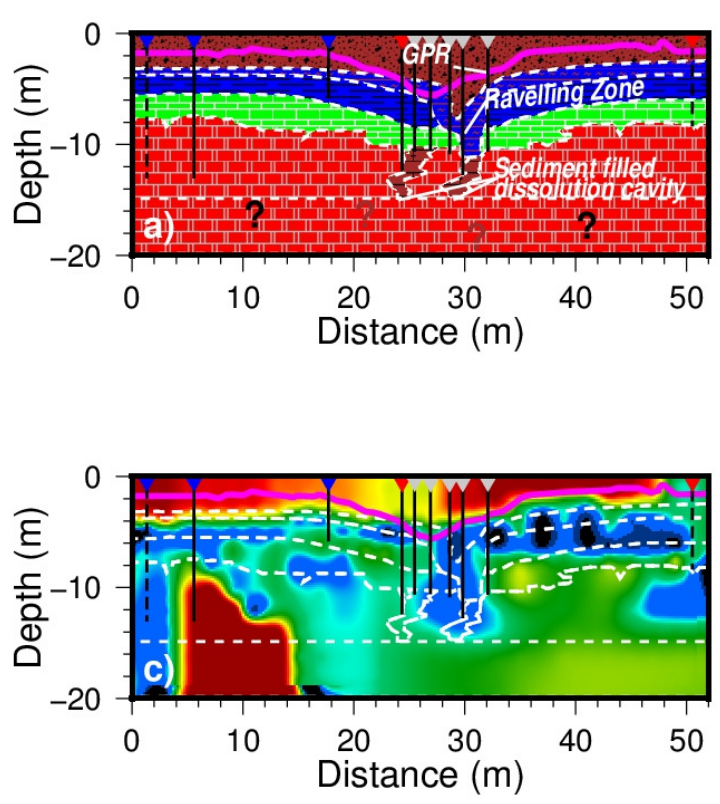

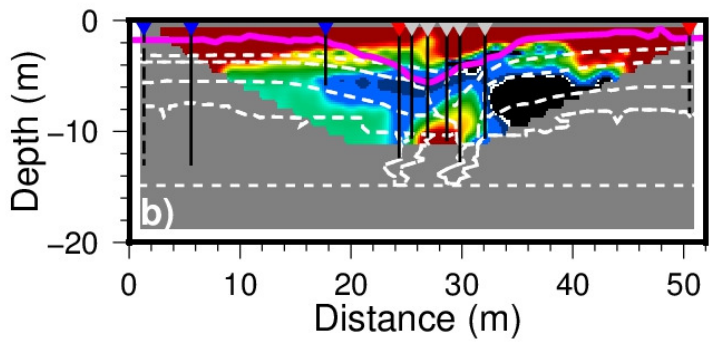

Legend

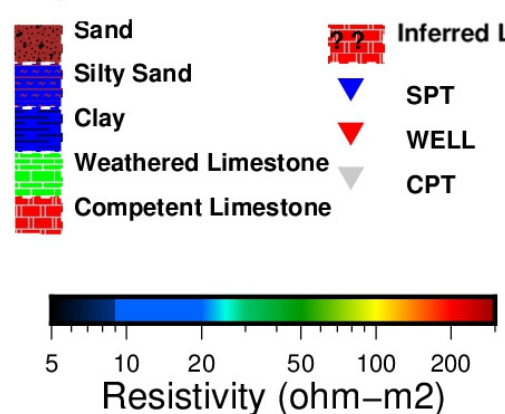

569

570

571

572

573

574

575

576

Figure 13. Line A in the covered karst USF Geopark (Figures 2 and 11 for location). (a) Geologic cross-section along Line A modified from Stewart and Parker (1992). (b) Resistivity image using conventional 28-electrode surface array with data misfit of $10.3 \%$ and (c) using a MERIT array with deep electrodes at $7.62 \mathrm{~m}$ and data misfit of $15 \%$. Magenta lines indicate depths to a strong GPR reflector, identified through auguering as a clayey silty sand layer within cover sands. Interpretations from boreholes located with in the survey length are shown with solid lines and those off the survey line are indicated by dashed lines. 
(3) There is an indication of a resistivity low near the surface around $25 \mathrm{~m}$, that coincides with a gentle surface depression where shallow angering shows thin $(>40 \mathrm{~cm})$ organic soil on the top but lacks the internal stratification and the clayey silty sand layer observed in other auger holes. The organic layer is inferred to accumulate solely near the sinkhole depression because during wet seasons, organic deposits will be concentrated here and contribute to the observed low resistivity. (4) The dissolution cavity detected by Stewart and Parker (1992) at $28 \mathrm{~m}$ and it's overlying raveling coincide with a resistivity low at $\sim 28 \mathrm{~m}$ in the MERIT inversion. These raveling zones are generally too narrow to be resolved using conventional arrays. (5) Finally, there is considerable fine scale complexity in the resistivity images

On line B (Figure 14), a GPR profile shows 3-4m depressions in the depth to a clay-rich layer at $20 \mathrm{~m}$ and at $49 \mathrm{~m}$. The GPR reflector depression at $20 \mathrm{~m}$ overlies a zone of thick clay, where limestone was not reached by a CPT to $>14 \mathrm{~m}$ (CPT16; Figure 14). In contrast the depression at $49 \mathrm{~m}$ overlies a zone of thickened sands, but limestone at $11.3 \mathrm{~m}$ depth (B4, Figure 14). The boring results show large lateral variability in the cover sediments; clearly the raveling process of sediments over limestone is highly locally heterogeneous. We infer that sediments infilled a limestone dissolution feature at $20 \mathrm{~m}$, but that this is no longer a site of active dissolution. The overlying sediments have had time to be well compacted, as seen in the relatively high SPT values in B3 (Figure 14b). In contrast, above the GPR reflector depression at $\sim 49 \mathrm{~m}$, a surficial lens of organic soil, $8 \mathrm{~m}$ wide and up to $80 \mathrm{~cm}$ thick, is seen in both GPR and B4 (Figure 14a and b). We speculate that the second sinkhole is active with loose soil populated by plant growth during wet seasons. The complex stratigraphy and low SPT values at B4 further suggest a zone of active raveling.

Both MERIT and surface-only resistivity arrays show good agreement with undulations in the sandclay contact seen with both GPR and coring. Below this contact, the MERIT profile (Figure 14e) shows better agreement with geological results than the surface profile with equal $5 \mathrm{~m}$ spacing (Figure 14c), in that MERIT shows a thick low-resistivity zone coincident with the thick clay recorded at CPT16 at $20 \mathrm{~m}$. The surface array with $2.5 \mathrm{~m}$ spacing also partly shows the presence of thicker clay around $20 \mathrm{~m}$. The MERIT results suggest high-resistivity limestone that is breached at $20 \mathrm{~m}$ and again on the northern end of the line. Borehole B $15 \mathrm{~m}$ from the northern end of the line (see Figure 11 for location) shows possible dissolution cavities indicated by absence of bedrock, voids and loss of circulation fluid, and low densities determined by SPT tests up to $56 \mathrm{~m}$. Both features are not sufficiently imaged by the surface arrays because they are located at depth and near the edge where the surface arrays suffer from poor sensitivity and resolution. 

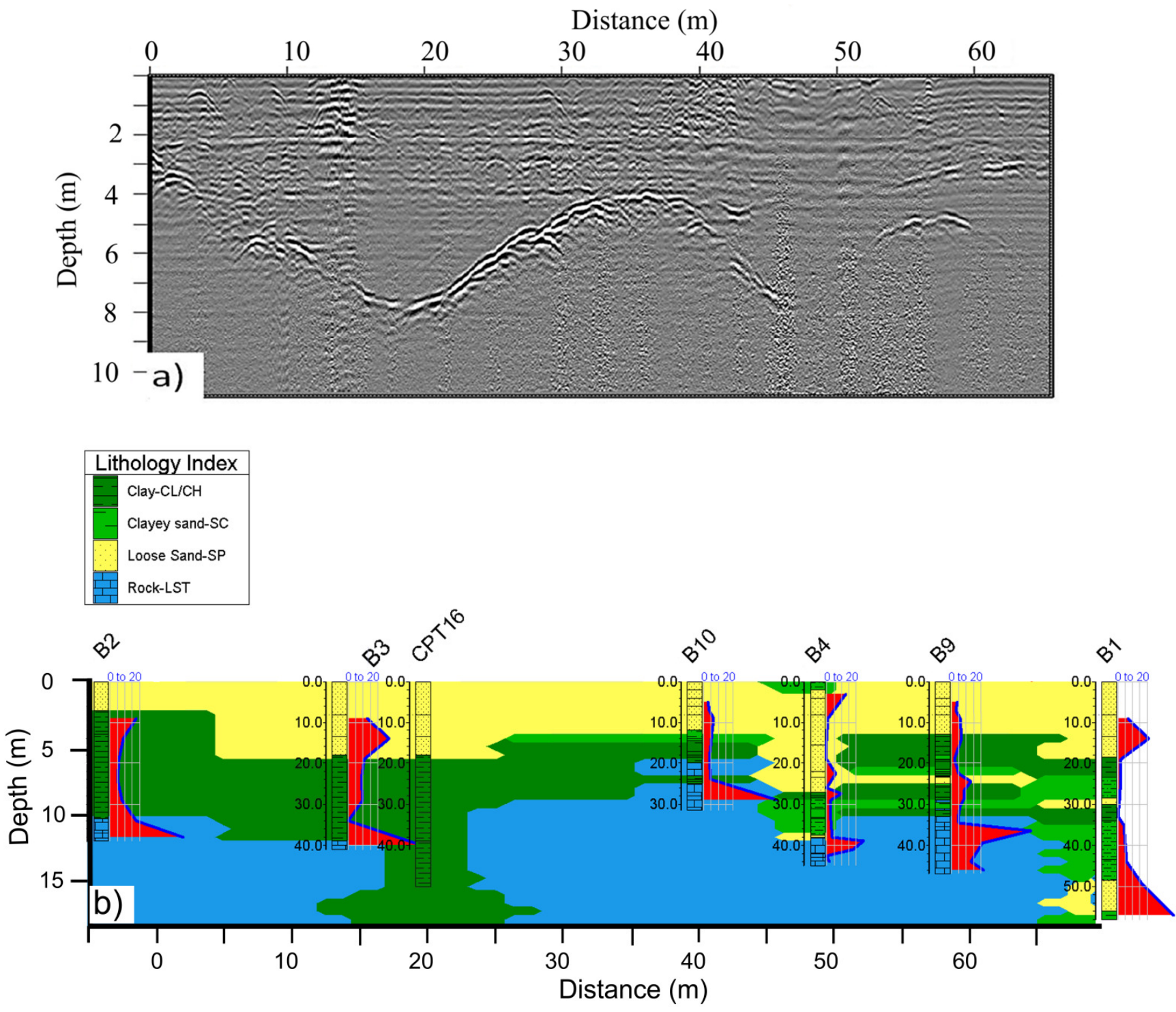

610

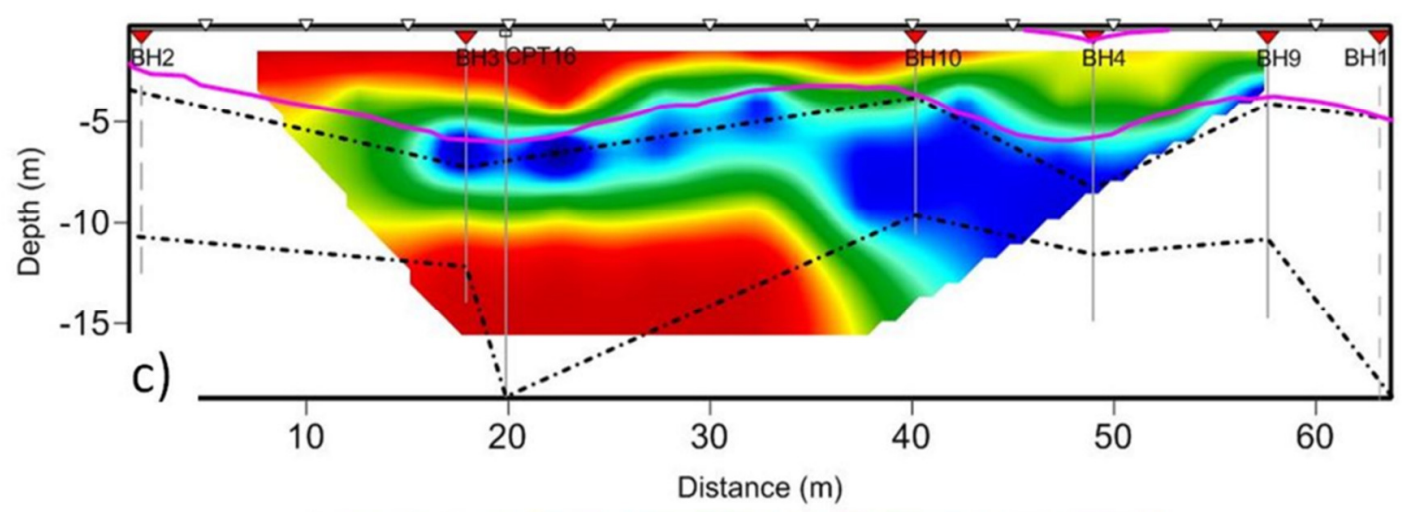



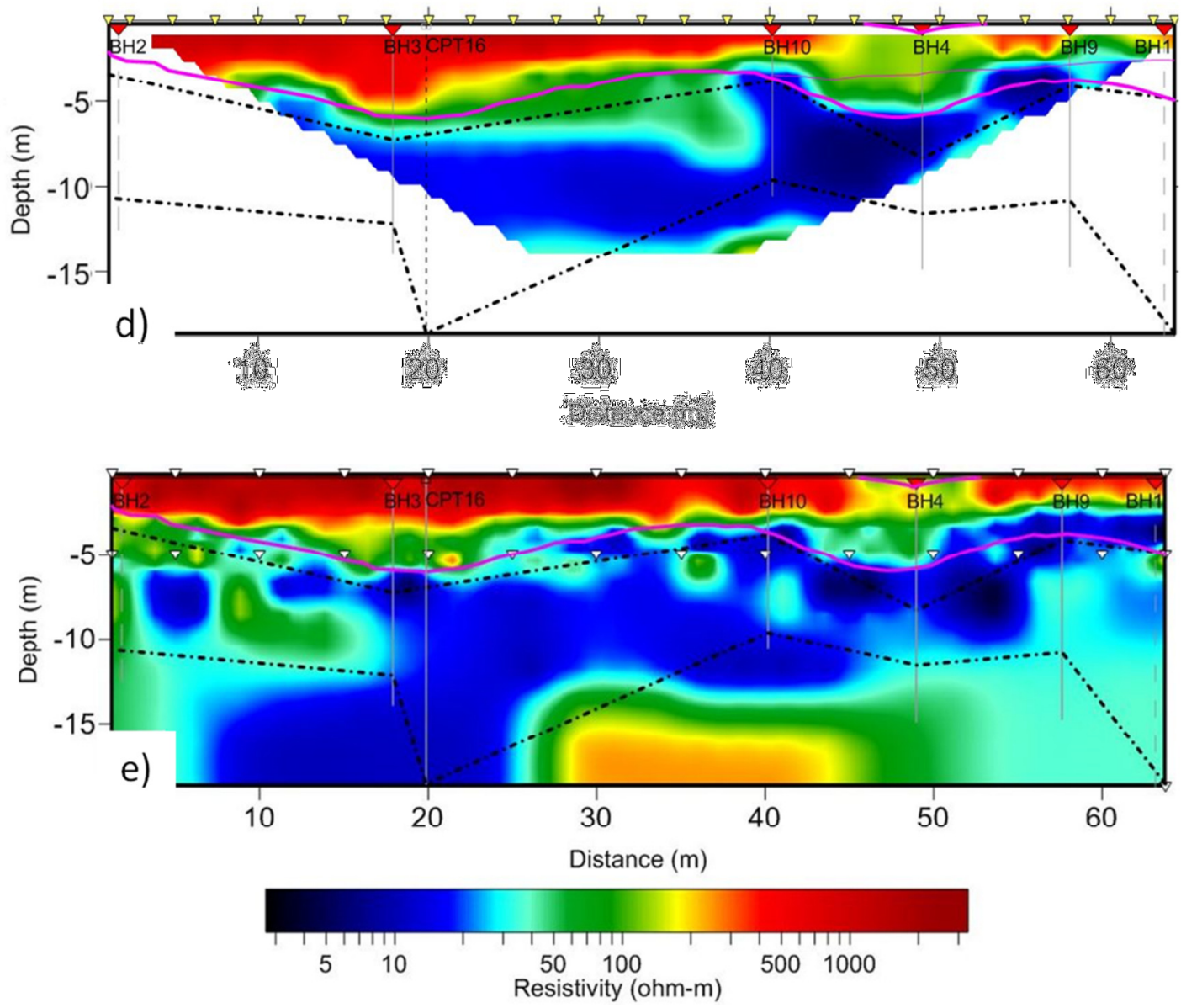

Figure 14. Geopark Resistivity result on Line B. (a) Ground peneterating radar showing depressions in clay-rich layer beneath sands. (b) Geologic cross-section along Line B based on 10 borehole logs and 1 CPT log. Red graphs show SPT values (sampled at $5 \mathrm{ft}$ interval) in a scale of 0 to 50 where small numbers indicate relatively loose sediment. BH1, BH2, and CPT16 are laterally offset from the resistivity line by less than $5 \mathrm{~m}$. (c) Resistivity images from Line B using conventional array with $5 \mathrm{~m}$ spacing (data misfit $=10.8 \%$ ) (d) and $2.5 \mathrm{~m}$ spacing (data misfit $=5.9 \%$ ) (e). Resistivity image using MERIT arrays with $5 \mathrm{~m}$ spacing (data misfit $=12 \%$ ). Dashed lines show lithologic contacts (top: sandclay; bottom: clay-limestone) recorded on cored sections of SPT borings. Most of these boreholes are located along the resistivity line except $\mathrm{BH} 1, \mathrm{BH} 2$ and $\mathrm{CPT} 16$ which are located with $5 \mathrm{~m}$ of the resistivity line.

5.2 Field case study 2: Landfill site

This case study site is a storage facility in Tampa, Florida, undergoing differential settlement in an urban setting with limited access. 


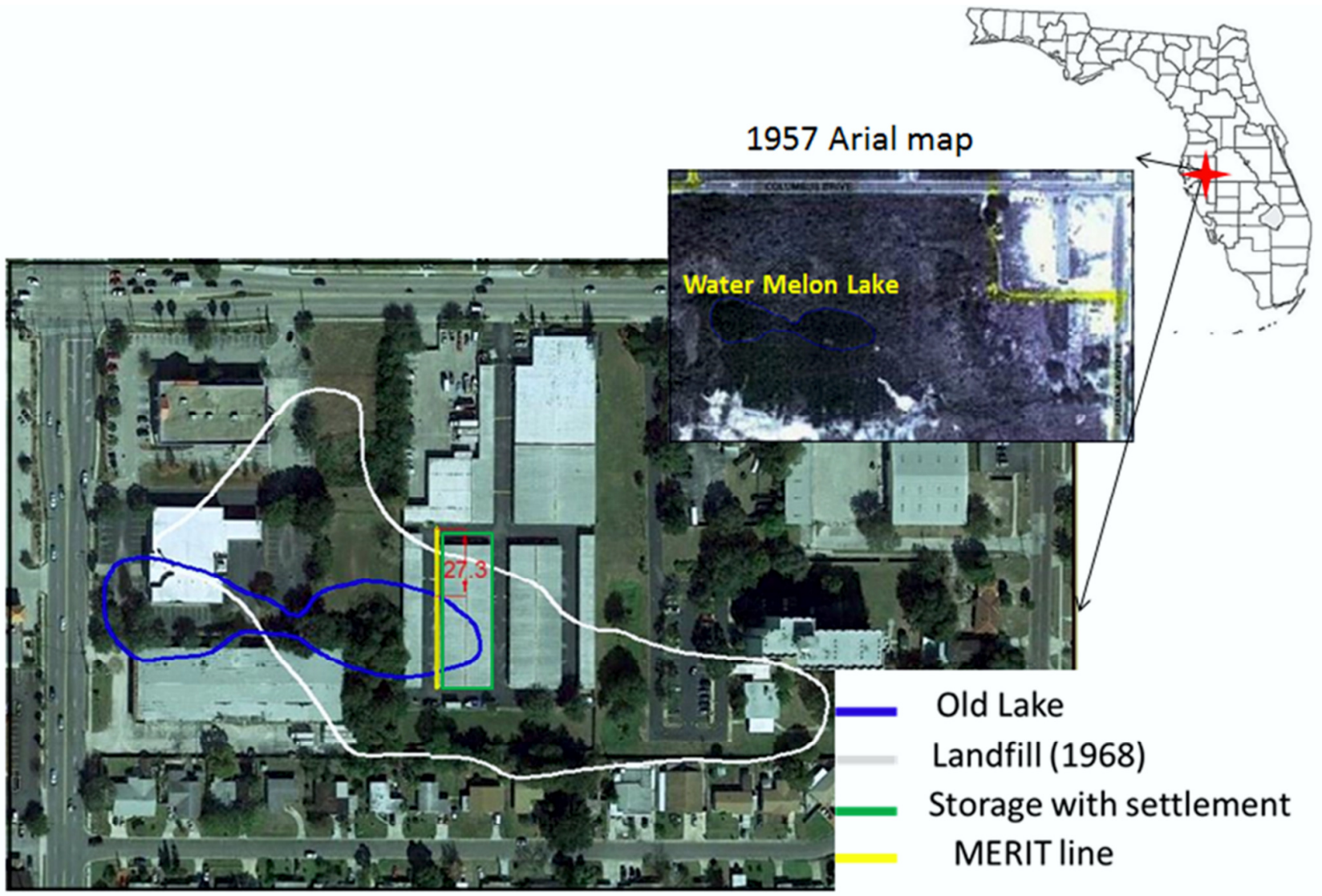

630

631

632

633

634

635

636

637

638

639

640

641

642

643

644

645

646

Figure 15. Differential settlement at a landfill constructed over an old lake, Water Melon Lake in Tampa, Florida, USA. The lake boundary is mapped from a 1957 aerial photograph and the landfill boundary from a 1968 aerial photograph. A 1972 aerial photograph shows that the landfill was extended north and west of the 1968 boundary. 27.3 indicate the distance in meters from the north edge of the resistivity line to the boundary of the infilled Water Melon lake. The southern edge of the resistivity line is $6 \mathrm{~m}$ from the edge of the old lake. The north edge of the line corresponds to the starting point of the resistivity survey.

The site was a landfill, active between 1968-1972 based on aerial photograph records (Figure 15). The landfill partially infilled an old sinkhole lake (Water Melon lake). The uppermost part of the fill is compacted and levelled. A borehole (BH1 on Figure 16, $32 \mathrm{~m}$ from the northern end of the resistivity line on Figure 15) shows the uppermost fill as asphalt and more compacted soil (possibly material reworked from the natural ground), underlain by relatively loose landfill material containing fragments of wood, red bricks and other materials. The drilling was terminated at $7.3 \mathrm{~m}$ due to complete water loss, without reaching any kind of bedrock material. Historical records of the landfill construction also confirm similar information. The current structures on the site are simple, one floor storage buildings. The middle part of the building highlighted in green on Figure 15 has experienced significant settlement, with cracks and offsets in the roof. 
A resistivity survey was carried out as part of an investigation of the cause of the differential settlement and its relation to the old landfill activity. The $65 \mathrm{~m}$-long survey occupied the maximum available length on site (Figure 15). 14 deep electrodes were implanted at $6.57 \mathrm{~m}$ depth and $5 \mathrm{~m}$ spacing with a total installation time of $7 \mathrm{hr}$. The resistivity survey installation is located parallel to and $1 \mathrm{~m}$ east of a vapor extraction trench installed to monitor the environmental impact of the landfill, and $\sim 1 \mathrm{~m}$ east of the settling building. The old lake boundary is $27.3 \mathrm{~m}$ from the northern end of the resistivity line and is $6 \mathrm{~m}$ from the southern end. The maximum differential settlement in the building is at $\sim 32 \mathrm{~m}$. The proximity of the old lake boundary and maximum differential settlement suggests the landfill is significantly thicker over the old lake, than on surrounding material.

The average noise level in the surface field data is $0.9 \%$. For the MERIT arrays, the field measurement included reciprocal readings and has an average noise level of $0.6 \%$ and an average reciprocal error of $0.4 \%$. These reciprocal errors were used to weight the observed data during the inversion. The contact resistance for both surface and MERIT electrodes is also very comparable. For example, the maximum and average contact resistance for the surface electrodes is $456 \Omega$ and $295 \Omega$ and $484 \Omega$ and $277 \Omega$ for the MERIT electrodes. Also on Line B above (Figure 14), similar contact resistance was observed for surface and MERIT electrodes with maximum and average value of $3470 \Omega$ and $1395 \Omega$ for surface arrays and $4826 \Omega$ and $1120 \Omega$ for the MERIT arrays.
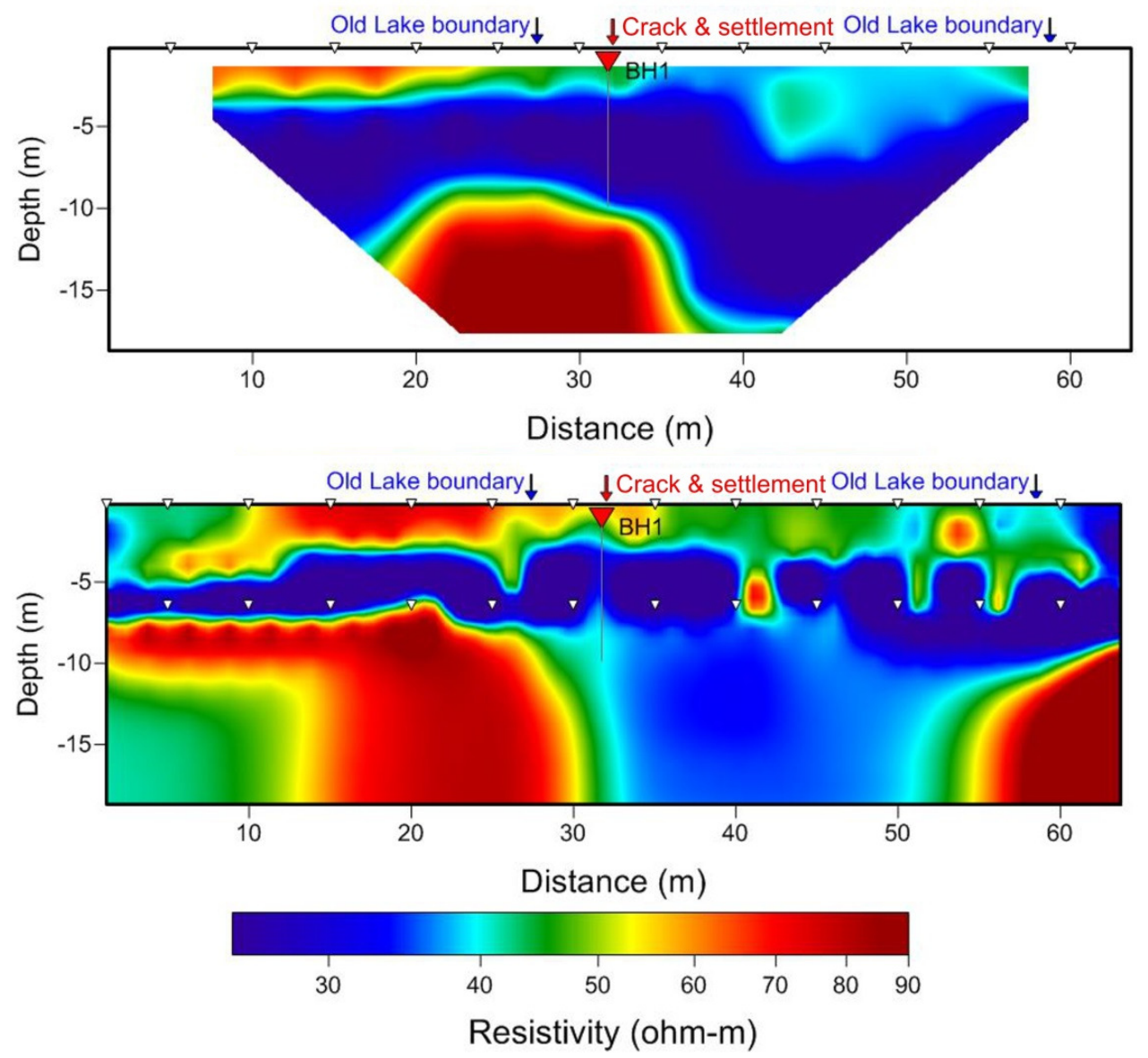
Figure 16. Resistivity results from the profile over an old landfill shown as yellow line on Figure 15. Inverted resistivity image using conventional array (left) and MERIT array (right). Data misfits are $3.1 \%$ and $3.7 \%$ for the conventional array and MERIT array respectivley. White dots show electrode locations and left end of the line points towards north.

The results from both the surface and MERIT surveys (Figure 16) show the contact between relatively resistive asphalt and compacted top layer and a lower conductive unit of landfill material. Most importantly, both images show a sharp resistivity boundary at 8-10 m depth, interpreted as the contact between the landfill material and the higher resistivity bedrock. This deep high-resistivity layer is discontinuous; it is absent south of $\sim 35 \mathrm{~m}$ from the surface resistivity inversion, and absent between $\sim 30 \mathrm{~m}$ and $55 \mathrm{~m}$ in the MERIT image. We interpret this gap in the deep resistive layer as a result of the old lake, subsequently filled. This interpretation is supported by the differential settlement described above. We can then assess the resistivity results against the known lake boundaries. The MERIT image shows a slightly better fit to the northern lake boundary. Notably, the MERIT array also shows the southern lake boundary, which is outside the zone of resolution of the surface array. This site is thus an example of the utility of the MERIT geometry in a setting where array lengths are limited.

The data misfit comparison between the surface and MERIT arrays shows that the MERIT arrays have relatively higher data misfit compared to the conventional surface arrays (Figure 13 for Line A, Figure 14 for Line B and Figure 16 for Landfill site). For Line A and Line B, while both arrays do a good job of capturing the near-surface variations, they both have higher data misfit compared to the results at the Landfill site. This could be related to the difference in the degree of complexity of the underlying karst structure in the two sites.

Comparing the data misfit of the MERIT inverted results from the Landfill site and Line B at the Geopark (Figure 14), it can be seen that the data misfit is significantly lower for the Landfill site although reciprocal error was used to suppress noisy data points on both. One explanation for that is the overall better data quality observed on the Landfill data compared to Line B. For example, the maximum contact resistance for Line B was $4826 \Omega$. Even though this number is lower than the commonly accepted value of $5000 \Omega$ (AGI, 2005), it is 10 times greater than the maximum contact resistance value observed for the Landfill site $(484 \Omega)$. Similarly, the average noise level $(1.7 \%)$ and average reciprocal error (3.0\%) for Line B again are higher than what is observed for the Landfill site $(0.6 \%$ and $0.4 \%)$.

6. Conclusion

2D surface resistivity surveys have fundamental limitations in depth of resolution, particularly at the ends of the array. These problems can limit the utility of the method at sites with limited working space. The problem is exacerbated by the presence of shallow conductive layers. Installation of a buried array of electrodes extends the depth of resolution and expands the zone of resolution to the ends of the array. This array geometry, referred to as multi-electrode resistivity implant technique (MERIT), is examined with synthetic models, laboratory experiments, and field case studies. In the 
field the deep electrodes are implanted using robust direct push technique using self-driving pointed electrodes. In practice, we find-

- Depth of resolution can be approximately doubled over that of a conventional surface array of equal length.

- Decrease in depth of penetration due to shallow clay layers is much less in MERIT arrays compared to conventional surface arrays.

- Good resolution is obtained up to the ends of the array, with some sensitivity (as expected) to features beyond the ends of the line.

- Improved resolution of geometries and absolute resistivity values are obtained for features between the surface and buried arrays.

- Because of geometric effects, the method is inherently somewhat noisier than surface arrays. Inversion artefacts appear close to the depth of the buried electrodes, analogous to the artefacts that appear close to electrodes in cross-borehole surveys.

- Inversion results are improved when reciprocal measurements are used to reduce the weight of noisy data in the inversion.

Acknowledgements

We would like to thank the editor and reviewers for their insightful comments which have helped to improve this paper. We also would like to thank G3 group for funding the research. This paper is published with the permission of the Executive Director of the British Geological Survey (NERC).

References

1. AGI (2005). Sting R1 instruction manual, release 01.01.38. Advanced Geosciences, Inc., Austin, Texas

2. Ahmed M Youssef, Hesham El-Kaliouby and Yasser A Zabramawi (2012). Sinkhole detection using electrical resistivity tomography in Saudi Arabia. Journal of Geophysics and Engineering 9, 655-663. Online publication date: 1-Dec-2012. Read More: http://library.seg.org/doi/abs/10.1190/1.1443142"

3. Auken E., Pellerin L., Christensen N.B. and Sørensen, K. (2006). A survey of current trends in near-surface electrical and electromagnetic methods. Geophysics 71, G249-G260.

4. Batayneh, A. T., et al. (2002). Use of ground-penetrating radar for assessment of potential sinkhole conditions: An example from Ghor al Haditha area, Jordan, Environ. Geol., 41, 977983.

5. Beck, B. F., and S. Sayed (1991).The sinkhole hazard in Pinellas County: A geologic summary for planning purposes, Rep. 90-91-1, 140 pp., Florida Sinkhole Res. Inst., Orlando, FL.

6. Benson, R. C., and L. J. La Fountain (1984). Evaluation of subsidence or collapse potential due to subsurface cavities, in Sinkholes: Their Geology, Engineering, and Environmental Impact: Proceedings of the First Multidisciplinary Conference on Sinkholes, edited by B. F. Beck, pp. 201-215, A. A. Balkema, Brookfield, Vt.

7. Carpenter, P. J., et al. (1998). Geophysical character of buried sinkholes on the Oak Ridge Reservation, Tennessee, J. Environ. Eng. Geophys., 3, 133-146.

8. Chambers, J.E., Wilkinson, P.B., Wealthall, G.P., Loke, M.H., Dearden, R., Wilson, R., Allen, D., and Ogilvy, R.D. (2010). Hydrogeophysical imaging of deposit heterogeneity and 
groundwater chemistry changes during DNAPL source zone bioremediation. Journal of Contaminant Hydrology, 118, 43-61.

9. Cherkaeva, E. and Tripp, A.C.(1996). Optimal survey design using focused resistivity arrays, IEEE Trans. Geosci. Remote Sens., 34, 358-366.

10. Dahlin, T. (2001). The development of DC resistivity imaging techniques. Computers \& Geosciences, 27(9), 1019-1029.

11. Daily, W., and Owen, E. (1991). Cross-borehole resistivity tomography. Geophysics, 56(8), 1228-1235.

12. Daniels, J.J., B. Allred, A. Binley, D. Larecque, and D. Alumbaugh, (2005), Hydrogeophysical case studies in the vadose zone, in, Hydrogeophysics, Y. Rubin and S.S. Hubbard, eds, Springer, p. 413-440.

13. Danielsen B.E. and Dahlin T. (2010). Numerical modeling of resolution and sensitivity of ERT in horizontal boreholes. Journal of Applied Geophysics, 70, 245-254.

14. Dobecki, T. L., and S. B. Upchurch (2006). Geophysical applications to detect sinkholes and ground subsidence, The Leading Edge, 25, 336-341.

15. El-Qady, G., Hafez, M., Abdalla, M. A., and Ushijima, K. (2005). Imaging subsurface cavities using geoelectric tomography and ground-penetrating radar.Journal of Cave and Karst studies, 67(3), 174-181.

16. Florida Senate Interim Report, 2010. Issues Relating to Sinkhole Insurance. Interim Report 2011-104. https://www.flsenate.gov/UserContent/Session/2011/Publications/InterimReports/pdf/2011104bi.pdf/(accessed 18 Aug. 2016).

17. Furman, A., Ferr'e, T.P.A. and Warrick, A.W. (2004). Optimization of ERT surveys for monitoring transient hydrological events using perturbation sensitivity and genetic algorithms, Vadose Zone J., 3, 1230-1239.

18. Gibson, P. J., Lyle, P., and George, D. M. (2004). Application of resistivity and magnetometry geophysical techniques for near-surface investigations in karstic terranes in Ireland. Journal of Cave and Karst Studies, 66(2), 35-38.

19. Hagrey, S. A. al and Petersen, T. (2011). Numerical and experimental mapping of small root zones using optimized surface and borehole resistivity tomography: Geophysics, 76(2), G25G35.

20. Harro, D., Kruse, S. (2013). Improved imaging of covered karst with the multi-electrode resistivity implant technique. NCKRI Symposium 2. Proceedings of the 13th Multidisciplinary Conference on Sinkholes and the Engineering and Environmental Impacts of Karst. Carlsbad, New Mexico, US.

21. Hennig, T. and Weller, A. (2005). Two dimensional object orientated focusing of geoelectrical multi-electrode measurements. Proceedings of the $11^{\text {th }}$ meeting of the EAGE Near Surface Geophysics Conference, Palermo, Italy.

22. Kiflu, H., Wightman, M., and Kruse, S. (2013). Statistical analysis of GPR and SPT methods for sinkhole investigation in covered karst terrain, west-central Florida, USA. NCKRI Symposium 2. Proceedings of the 13th Multidisciplinary Conference on Sinkholes and the Engineering and Environmental Impacts of Karst. Carlsbad, New Mexico, US.

23. Kruse, S. E., Brudzinski, M. R., and Geib, T. L. (1998). Use of electrical and electromagnetic techniques to map seawater intrusion near the Cross-Florida Barge Canal. Environmental and Engineering Geoscience, 4(3), 331-340. 
24. Kruse, S., Grasmueck, M., Weiss, M., and Viggiano, D. (2006). Sinkhole structure imaging in covered Karst terrain. Geophysical Research Letters, 33(16).

25. Kruse, S. (2014). Three-dimensional GPR imaging of complex structures in covered karst terrain, 15th International Conference on Ground Penetrating Radar, Brussels, Belgium, Conference programme, $4 \mathrm{pp}$.

26. LaBrecque, D.J., Ramirez, A.L., Daily,W.D., Binley, A.M., Schima, S.A. (1996). ERT monitoring of environmental remediation processes. Measurement Science and Technology 7 (3), 375-385.

27. Legault, J.M., Carriere, D., Petrie, L. (2008). Synthetic model testing and distributed acquisition dc resistivity results over an unconformity uranium target from the Athabasca Basin, northern Saskatchewan. The Leading Edge 27 (1), 46-51.

28. Lesmes, D.P. and S.P. Friedman, (2005). Relationships between the electrical and hydrogeological properties of rocks and soils, in, Hydrogeophysics, Y. Rubin and S.S. Hubbard, eds, Springer, p. 87-128.

29. Liu, C., Song, C., Lu, Q., Liu, Y., Feng, X., and Gao, Y. (2015). Impedance inversion based on L1 norm regularization. Journal of Applied Geophysics, 120, 7-13.

30. Loke, M. H., and Barker, R. D. (1996). Practical techniques for 3D resistivity surveys and data inversion. Geophysical prospecting, 44(3), 499-523.

31. Loke M.H., Acworth I. and Dahlin T., (2003). A comparison of smooth and blocky inversion methods in 2D electrical imaging surveys. Exploration Geophysics 34, 182-187.

32. Loke, M. H. (2010). Tutorial: 2D and 3D electrical imaging surveys (pp. 30-32).

33. Loke, M.H., Chambers, J.E., Rucker, D. F., Kuras, O. and Wilkinson, P. B. (2013). Recent developments in the direct-current geoelectrical imaging method. Journal of Applied Geophysics, 95, 135-156.

34. Loke, M.H, Wilkinson, P.B., Chambers, J.E., and Strutt, M. (2014a). Optimized arrays for 2D cross-borehole electrical tomography surveys. Geophysical Prospecting, 62, 172-189.

35. Loke, M. H., Wilkinson, P. B., Uhlemann, S. S., Chambers, J. E., and Oxby, L. S. (2014b). Computation of optimized arrays for 3-D electrical imaging surveys. Geophysical Journal International, 199(3), 1751-1764.

36. Loke M.H, Kiflu H.G., Wilkinson P.B., Harro D., and Kruse S. (2015). Optimized array for 2D resistivity surveys with combined surface and deep arrays. Near Surface Geophysics, in press.

37. Meju, M. (2006). Geoelectrical characterization of covered landfill sites: a process-oriented model and investigative approach. In Applied hydrogeophysics (pp. 319-339). Springer Netherlands

38. Menke, W. (1984). Geophysical Data Analysis: Discrete Inverse Theory Academic. New York.

39. Nenna, V., Pidlisecky, A., and Knight, R. (2011). Informed experimental design for electrical resistivity imaging. Near Surface Geophysics, 9(5), 469-482.

40. Noel, M., and Xu, B. (1991). Archaeological investigation by electrical resistivity tomography: a preliminary study. Geophysical Journal International, 107(1), 95-102.

41. Paasche H., Werban U. and Dietrich P. (2009). Near-surface seismic traveltime tomography using a direct-push source and surface-planted geophones, Geophysics, 74 G17-G25.

42. Perri, M.T., Cassiani, G., Gervasio, I., Deiana, R., Binley, A. (2012). A saline tracer test monitored via both surface and cross-borehole electrical resistivity tomography: comparison of time-lapse results. Journal of Applied Geophysics 79, 6-16. 
43. Pidlisecky A, Knight R, Haber E. (2006). Cone-based electrical resistivity tomography. Geophysics 71 (4).

44. Power C., Gerhard J.I., Tsourlos P., Soupios P., Simyrdanis K. and Karaoulis M. (2015). Improved time-lapse electrical resistivity tomography monitoring of dense non-aqueous phase liquids with surface-to-horizontal borehole arrays. Journal of Applied Geophysics, 112, 1-13.

45. Press, W.H. , Teukolsky, S.A., Vetterling, W.T. and Flannery, B.P, 2007. Numerical Recipes in C (Third Edition). Cambridge University Press, Cambridge, UK.

46. Robinson, J., Slater, L., Johnson, T., Shapiro, A., Tiedeman, C., Ntarlagiannis, D.and Lane, J. (2015). Imaging Pathways in Fractured Rock Using Three-Dimensional Electrical Resistivity Tomography. Groundwater.

47. Singha, K., Day-Lewis, F.D., Johnson, T., and Slater, L.D. (2014). Advances in interpretation of subsurface processes with time-lapse electrical imaging. Hydrological Processes, doi: 10.1002/hyp.10280, $28 \mathrm{p}$.

48. Slater, L., Zaidman, M. D., Binley, A. M., and West, L. J. (1997). Electrical imaging of saline tracer migration for the investigation of unsaturated zone transport mechanisms. Hydrology and Earth System Sciences Discussions, 1(2), 291-302.

49. Slater L., Binley A.M., Daily W. and Johnson R. (2000). Cross-hole electrical imaging of a controlled saline tracer injection. Journal of Applied Geophysics 44, 85-102.

50. Stewart, M. and Parker J. (1992). Localization and seasonal variation of recharge in a covered karst aquifer system, Florida, USA, in Hydrogeology of Selected Karst Regions, H. Palos and W. Back, eds., International Contributions to Hydrogeology, Vol. 13, International Association of Hydrogeologists.

51. Stewart, M. and Parker J. (1992). Localization and seasonal variation of recharge in a covered karst aquifer system, Florida, USA, in Hydrogeology of Selected Karst Regions, H. Palos and W. Back, eds., International Contributions to Hydrogeology, Vol. 13, International Association of Hydrogeologists.

52. Stewart, M., (1998). The Florida water wars, a geologic perspective. Geotimes, 43, 3, p. 24-27.

53. Stummer P., Maurer H. and Green A. (2004). Experimental design: Electrical resistivity data sets that provide optimum subsurface information. Geophysics 69, 120-129. Telford, W. M., and Sheriff, R. E. (1990). Applied geophysics (Vol. 1). Cambridge university press.

54. Tihansky AA. (1999). Sinkholes, West-Central Florida. U.S. Geological Survey Karst Interest Group Proceedings, St. Petersburg, Florida, February 13-16, 2001: US Geological Survey Water-Resources Investigations Report 01-4011.

55. Tsourlos, P. I., and Ogilvy, R. D. (1999). An algorithm for the 3-D inversion of tomographic resistivity and induced polarisation data: preliminary results. Journal of the Balkan Geophysical Society, 2(2), 30-45.

56. United States Environmental Protection Agency (1998). Geophysical techniques to locate DNAPLs: Profiles of federally funded projects, EPA 542-R-98-020, Member Agencies of the Federal Remediation Technologies Roundtable, 31p.

57. United States Environmental Protection Agency (2005). Groundwater sampling and monitoring with direct push technologies, EPA 540/R-04/005, Office of Solid Waste and Emergency Response, 78p.

58. Wilkinson P.B., Chambers J.E., Meldrum P.I., Ogilvy R.D. and Caunt S. (2006a). Optimization of array configurations and panel combinations for the detection and imaging of abandoned mineshafts using 3D cross-hole electrical resistivity tomography. Journal of Environmental and Engineering Geophysics 11, 213-221. 
59. Wilkinson P.B., Meldrum P.I., Chambers J.E., Kuras, O. and Ogilvy R.D. (2006b). Improved strategies for the automatic selection of optimized sets of electrical resistivity tomography measurement configurations. Geophysical Journal International 167, 1119-1126.

60. Wilkinson, P. B., Chambers, J. E., Lelliott, M., Wealthall P. and Ogilvy, R. D. (2008). Extreme sensitivity of cross-hole electrical resistivity tomography measurements to geometric errors. Geophysical Journal International 173, 49-62.

61. Wilkinson, P.B., Loke, M.H., Meldrum, P.I., Chambers, J.E., Kuras, O., Gunn, D.A. and Ogilvy, R.D. (2012). Practical aspects of applied optimized survey design for electrical resistivity tomography. Geophysical Journal International 189, 428-440.

62. Yeboah-Forson, A, Comas, X., and Whitman, D. 2014. Integration of electrical resistivity imaging and ground penetrating radar to investigate solution features in the Biscayne Aquifer. Journal of Hydrology. 515: 129-138. 